\title{
Quantitative Ultrastructure of la Boutons in the Ventral Horn: Scaling and Positional Relationships
}

\author{
Joseph P. Pierce ${ }^{a}$ and Lorne M. Mendell \\ Department of Neurobiology and Behavior, State University of New York at Stony Brook, Stony Brook, New York 11794
}

Three physiologically characterized spindle (group la) afferents were labeled by the intracellular injection of HRP and were processed for light-level reconstruction. Thirty-five boutons in the ventral horn were then selected for analysis. They were serially thin sectioned and characterized in terms of volume, total surface area and the surface area of apposition to postsynaptic neurons (apposed surface area), mitochondrial volume, vesicle and active zone features, relation to presynaptic contacts, postsynaptic profile size, and position within the terminal arbor. Virtually all of these characteristics were widely variable, both within the entire population and in the endings of a single fiber. Apposed surface area, mitochondrial volume, vesicle number, active zone vesicle number, active zone number, and total active zone area were highly correlated in a positive linear manner with bouton volume. This suggests a type of ultrastructural "size principle," in which the morphological features associated with synaptic release scale directly in proportion to bouton size. This pattern also extends to local circuit interactions: the extent of an la bouton's input from axoaxonal contacts ( $86 \%$ receive at least one axoaxonal contact) was directly proportional to its size. In addition, the characteristics of an la bouton were related to its position on the postsynaptic element and within the terminal arbor. Vesicle density, percentage mitochondrial volume, and active zone size increased as the postsynaptlc process decreased in size, while volume, apposed surface area, active zone number and area, and vesicle number all decreased as one moved downstream within a terminal branch, with the exception of the terminal bouton. Vesicle density also decreased as one moved away from the dorsal root entry zone.

[Key words: spindle afferent, motoneuron, vesicle, synapse, active zone, mitochondria]

Since the early studies of Lloyd (1946) the Ia afferent-motoneuron synapse in the spinal cord has remained as one of the

\footnotetext{
Received Dec. 15, 1992; revised May 5, 1993; accepted May 11, 1993

I his work was supported by NIH Grants NS-08239, NS-16996, and NS-14899. Drs. W. F. Collins III and H. R. Koerber participated in the initial stages of the work. Three-dimensional reconstructions were made by Ricardo Avila and Lisa Sobierajski using the Volvis system in the Howard Hughes Institute of Medical Research (Dr. Paul Adams, P.I.), in association with the Department of Computer Sciences, SUNY-Stony Brook. We also thank Ann Bushnell for technical support Dr. John Cabot for advice and the usc of his facilitics, Dr. Gary Lcwin for his comments on the manuscript and help with graphics, and Dr. Teri Milner for her comments on the manuscript.

Correspondence should be addressed to Dr. Lorne M. Mendell, Department of Neurobiology and Behavior, SUNY-Stony Brook, 550 Life Science Building, Stony Brook, NY 11794.

a Present address: Division of Neurobiology, Cornell University Medical College, 411 East 69th Street, New York, NY 10021.
}

Copyright (c) 1993 Society for Neuroscience $0270-6474 / 93 / 134748-16 \$ 05.00 / 0$ primary models for the study of synaptic function. The extensive divergence of Ia afferents in the ventral horn, the relative ease of recording from motoneurons, and the development of spiketriggered averaging have all contributed to the large amount of physiological data collected at this connection (reviewed by Henneman and Mendell, 1981). Quantal analysis has been applied to the examination of individual EPSPs (Kuno, 1964; Jack et al., 1981a; Redman and Walmsley, 1983). The findings suggest that Ia EPSPs are best modeled when it is assumed that release occurs from multiple sites with widely variable release probabilities. Recent studies indicate that the connections formed by an individual fiber on different motoneurons are variable, and are related to the characteristics of the contacted motoneuron (Koerber and Mendell, 1991).

The morphological analysis of the Ia-motoneuron synapse has been less extensive. The development of HRP staining techniques has allowed Ia fibers to be labeled and Ia contacts to be examined at the light and ultrastructural levels (Burke et al., 1979, 1988; Conradi et al., 1983; Fyffe and Light, 1984). However, these studies did not involve a quantitative analysis of Ia bouton characteristics. When this approach has been applied to the examination of other types of synapse, a wide degree of structural variability is usually demonstrated (Davey and Bennett, 1982; Tracey and Walmsley, 1984; Hongo et al., 1987; Harris and Stevens, 1988; Peters and Harriman, 1990).

Differences in synaptic morphology are frequently associated with differences in the physiological properties of the synapse. In Crustacea (Govind and Chiang, 1979; Atwood and Marin, 1983) and the frog (Propst and Ko, 1987), neuromuscular junction (NMJ) active zone (AZ) length is related to the level of transmitter release: synapses with high levels of output have longer active zones than those with low levels of output. Additionally, prolonged stimulation of the crustacean NMJ can modify physiological properties and morphological features in a concurrent manner. Stimulation of phasic motor axons in the crayfish (Lnenicka et al., 1986) or tonic motor axons in the lobster (Chiang and Govind, 1986) leads to increases in transmitter release over time, and increases in mitochondrial size, number, and vesicle accumulation (and at the lobster NMJ, the addition of AZ sites). A similar pattern of associated change has been observed in Aplysia (Bailey and Chen, 1989), where the sensitization of a sensory nerve synapse is related to an increase in the number and size of active zones and the number of vesicles; and in the rat dentate gyrus (Desmond and Levy, 1986), where the induction of long-term potentiation is correlated with increases in AZ size. Bower and Haberly (1986) have also suggested that synapses that exhibit facilitation have presynaptic endings with a much lower vesicle density than those that do not.

A quantitative analysis of Ia bouton ultrastructural charac- 
teristics, and in particular the extent of variability (both generally and within the endings of a single fiber), would thus seem to be justified in light of the physiological reports suggesting variable release properties. The present study is an attempt to examine these questions through the identification and serial reconstruction of Ia contacts in the ventral horn, at light and ultrastructural levels.

\section{Materials and Methods}

1. Identification, labeling, and tissue processing. Medial gastrocnemius (MG) Ia muscle afferent fibers in the lumbar spinal cord of the cat were identified physiologically and injected intra-axonally with HRP. Experimental animals were first deeply anesthetized with Nembutal (30 $\mathrm{mg} / \mathrm{kg}$, i.p.), and both the forelimb withdrawal reflex and carotid blood pressure were monitored. Supplemental intravenous doses were administered as necessary. $\mathrm{CO}_{2}$ levels were measured through a tracheal cannula, and core body temperature was monitored with a rectal probe and maintained between $36^{\circ} \mathrm{C}$ and $39^{\circ} \mathrm{C}$ (with lamps and a heating pad). The preparation was stabilized in a spinal frame, the lumbar enlargement was exposed, and the MG muscle nerve was dissected free in the popliteal fossa and placed on hook electrodes. All exposed tissues were covered with mineral oil pools also maintained between $36^{\circ} \mathrm{C}$ and $39^{\circ} \mathrm{C}$. The animal was then paralyzed with gallamine and artificially ventilated.

A micropipette filled with a $10 \% \mathrm{w} / \mathrm{v}$ solution of IIRP in Tris- $\mathrm{HCl}$ buffer containing $0.5 \mathrm{M} \mathrm{KCl}$ at $\mathrm{pH} 7.6$ was lowered through the dorsal columns in L7. MG afferent fibers were activated by peripheral nerve stimulation. Impaled fibers were identified as $\mathrm{MG}$ afferents by their orthodromic response to MG nerve stimulation, and as group Ia spindle afferents by their stretch sensitivity, their conduction velocity, and the location of the receptor in the exposed muscle belly. These were then iontophoretically injected with HRP using square-wave positive current (5-50 nA, 66\% duty cycle). After at least $5 \mathrm{hr}$, the experimental animal was perfused through the carotid artery with 1 liter of $0.5 \%$ paraformaldehyde and $2.5 \%$ glutaraldehyde in $0.1 \mathrm{M}$ phosphate buffer at $\mathrm{pH}$ 7.7. The lumbar enlargement was then removed and postfixed overnight in $0.5 \%$ paraformaldehyde in $0.1 \mathrm{M}$ phosphate buffer at $\mathrm{pH} 7.7$.

Serial $50 \mu \mathrm{m}$ parasagittal sections were cut on a vibratome and reacted with diaminobenzidine. The sections were then scanned at the light level and selected sections were postfixed in $2 \%$ osmium tetroxide in $0.1 \mathrm{~m}$ phosphate buffer ( $\mathrm{pH} \mathrm{7.2)}$ ) for $1 \mathrm{hr}$, dehydrated in a series of alcohol rinses, and embedded in Epon wafers. Selected portions of the wafers that contained labeled elements were excised and mounted on Epon blocks. Serial thin sections were cut on an ultramicrotome with a diamond knife, placed on slotted, Formvar-coated grids, and poststained with uranyl acetate and lead citrate for examination at the electron microscopic (EM) level using a JEOL 100C scope.

2. Analysis. Both slide-mounted and wafer-embedded sections were used to produce a reconstruction of the labeled fiber at the light level. The labeled fiber was examined at $400 \times$; the point of injection and the dorsal root entry (DRE) point were identified, and individual collateral arbors were drawn with a camera lucida attachment. Drawings from consecutive sections were merged by matching cut fiber ends, and compressed onto the parasagittal plane of section.

At the ultrastructural level, labeled boutons were located and photographed at both low $(500 \times)$ and high $(10,000 \times)$ magnifications. Lowmagnification micrographs allowed the matching of boutons with specific varicosities drawn at the light level (Fig. 1). High-magnification micrographs were taken of roughly every other section through the entire bouton. These photographic series formed the basis for the three-dimensional reconstruction and analysis of each identified bouton.

Bouton volume was calculated from each series of cross-sectional areas, measured with a drawing tablet, and the average section thickness $(80 \mathrm{~nm})$ was estimated from small folds on various sections (Small, 1968). At points of axon entry (where the axon expands into the bouton), a straight line was used to draw a boundary between the axon and the bouton. Bouton cross-sectional area was further subdivided into three types of area, based on regional differences described by Peters et al. (1976): (1) mitochondrial area, (2) vesicular area (regions where vesicles were found, but few microtubules), and (3) microtubule area (regions where microtubules were found, but few vesicles) (Fig. 2). The percentage of bouton volume occupied by mitochondria (percentage mitochondrial volume) was calculated by measuring percentage mitochondrial area through each series. Similarly, measurements of the total perimeter length and both the length and percentage of the perimeter apposed to the postsynaptic element (either dendritic or somal) yielded values for total surface area, the portion of the surface area apposed to the postsynaptic element (apposed surface area), and percentage of that apposition (percentage apposed surface), respectively.

Active zones were distinguished from puncta adhaerentia on the basis of the criteria presented by Peters et al. (1976): (1) an asymmetrical distribution of dense material and (2) the close association of synaptic vesicles, with individual sections being tilted to yield the best view of the synaptic membrane. The boundaries of active zones were defined using the boundaries of pre- and postsynaptic indicators (accumulated vesicles, a uniformly widencd synaptic cleft, a plaque of intercellular material, and a postsynaptic density), which were invariably in agreement. Serial bouton section tracings were aligned according to external and internal cues using Usson's reconstruction package (Calverley and Jones, 1990), and the merged image was rotated to present a direct view of the apposed surface. This image was then adjusted to generate a "folded-flat" active zone map, from which the total number of active zones (AZ number), the area (AZ size) and shape of each active zone, and the total area of all the active zones on a given bouton (total $A Z$ area) could be determined. In instances where multiple postsynaptic processes were contacted, each apposed region was considered separately.

Total vesicle number (vesicle number) was calculated by counting the number of vesicles in each section, and vesicle density was calculated by dividing by total vesicular arca [vesicle density was also determined as a function of both total area and total cytosolic area (total area minus total mitochondrial area)]. Since the vesicle density within vesicular regions seemed to reflect vesicle packing densities most accurately, use of the term "vesicle density" refers to this calculation unless otherwise noted. In all instances where active zones could be identified, a small, distinct group of vesicles could be found tightly clustered against the surface of the active zone (Fig. 2). These vesicles (which will be referred to as $A Z$ vesicles) were also counted separately, to yield values for total $A Z$ vesicle number ( $A Z$ vesicle number), $A Z$ vesicles as a percentage of the total vesicle number ( $A Z$ vesicle percentage), as a function of total active zone surface (AZ vesicles $/ \mu \mathrm{m}^{2} \mathrm{AZ}$ ), and as a function of the number of active zones (AZ vesicles/AZ). In several instances vesicles within a given section were counted twice by the same observer on 2 different days to ensure reproducibility (which was found to be within $5 \%$ ). All vesicle counts were adjusted to consider cut vesicles and lost caps by using a variation of Floderus's (1944) equation [count correction factor $=(t-h) /(t+D-2 h)$, where $t=$ section thickness, $80 \mathrm{~nm} ; D$ $=$ vesicle diameter, $80 \mathrm{~nm}$; and $h=$ the percentage of the radius lost as caps, estimated at $10 \%$, or $2 \mathrm{~nm}$ ].

Small boutons with flattened vesicles and clear cytoplasm, corresponding to Conradi's type P bouton (Conradi, 1969), were often seen in close association with labeled boutons. However, since the presence of reaction product in the labeled boutons tended to obscure postsynaptic densities and these boutons do not contain pronounced synaptic specializations (Holstege and Calkoen, 1990), it was difficult to establish whether presynaptic active zones were formed. For each labeled Ia bouton the number of associated $\mathrm{P}$ boutons was determined ( $\mathrm{P}$ bouton number), along with the fraction of those that also formed synapses with the postsynaptic element contacted by the Ia bouton ( $P$ bouton ratio), and the total and percentage surface area of the la bouton apposed to $\mathrm{P}$ boutons ( $\mathrm{P}$ bouton surface and $\mathrm{P}$ bouton percentage surface).

All of the values presented are extrapolations for the entire labeled bouton, based on the sections sampled. No compensation for shrinkage was applied, since the slight shrinkage caused by glutaraldehyde fixation (about 3\%; Hillman and Deutsch, 1978) was probably balanced by the slight expansion of HRP-labeled material embedded for EM (about 5\%; Örnung and Ulfhake, 1990).

The parameters of each bouton could then be measured, examined in relation to the whole population for interrelationships, and related to the position of the bouton (on the postsynaptic element, within the terminal field, and in the presynaptic arbor). The shortest diameter of postsynaptic dendritic profiles was mcasurcd as an indicator of distance from the soma (the distance to the soma was directly measured when possible, i.e., for proximal endings). Boutons that contacted the soma were assigned a diameter of $10 \mu \mathrm{m}$, which was larger than any of the diameters measured for contacts on the most proximal dendrites. Descriptive statistics for each variable will be presented as mean \pm the SD. Correlation analysis with Fisher's $r$-to- $z$ transformation for significance, unpaired $t$ tests, and nested ANOVAs were used to test rela- 
Fiber 5

Fiber 11

Fiber 16

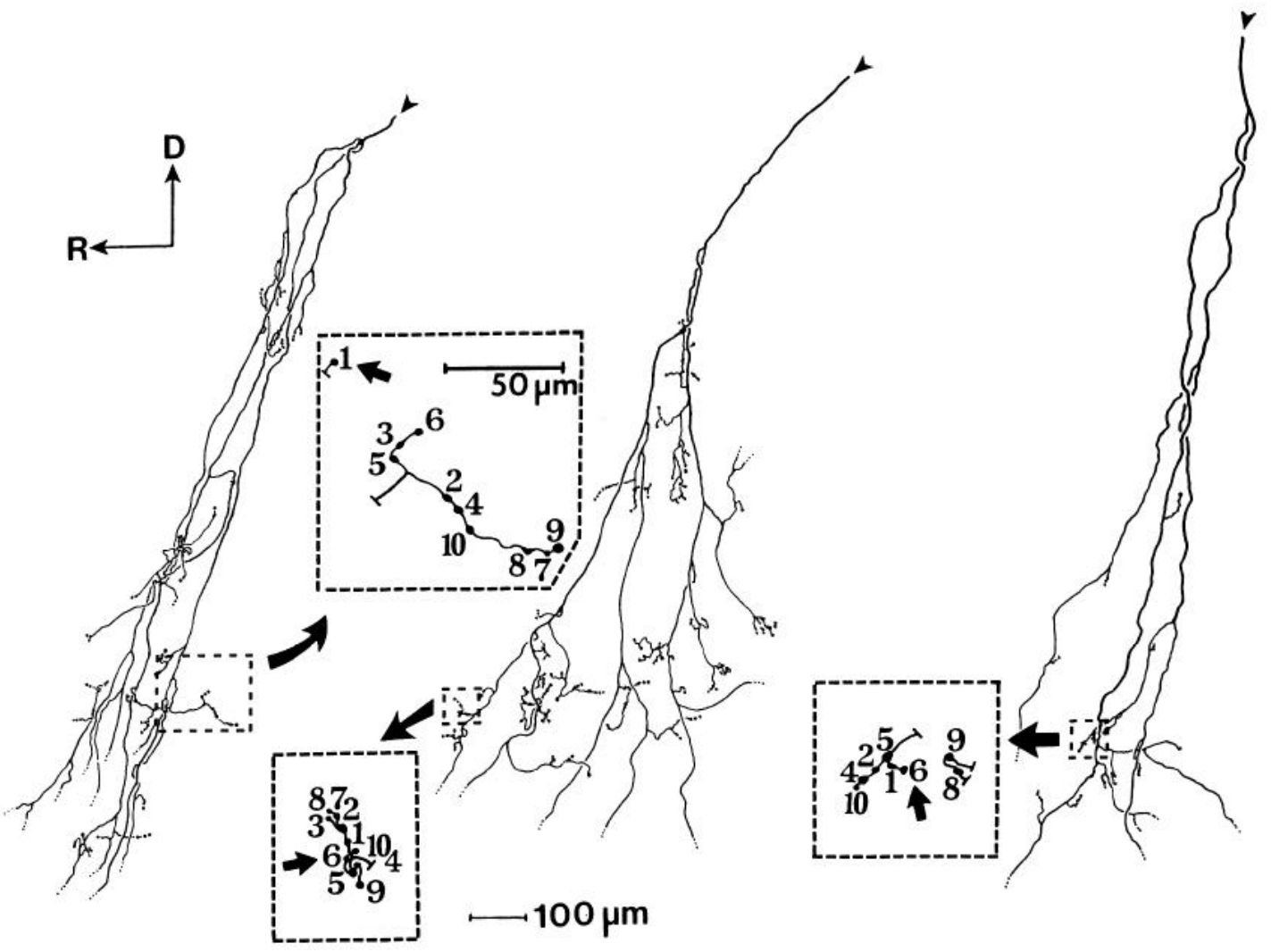

Bouton 5-1 Bouton 11-6 Bouton 16-6

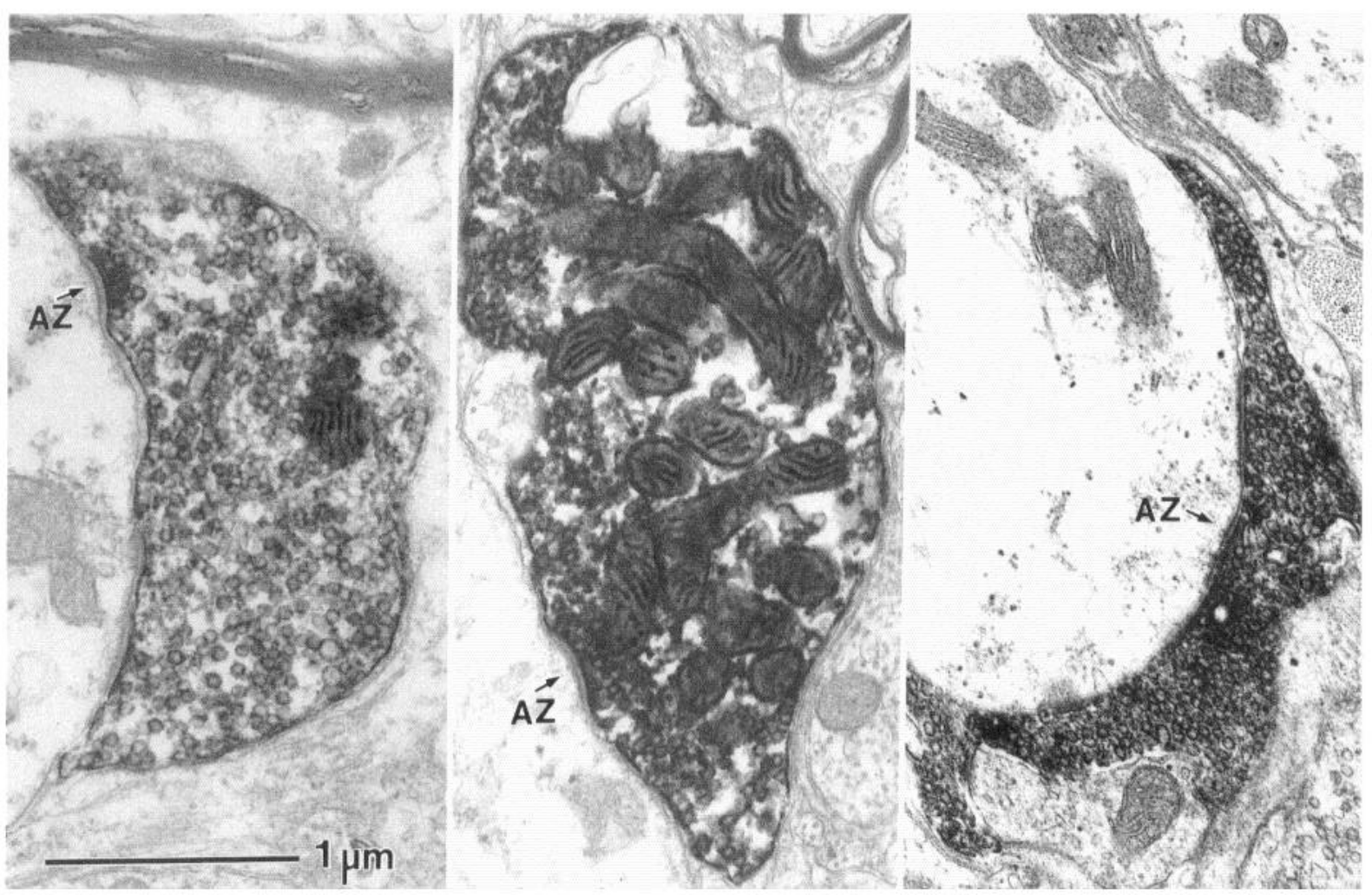




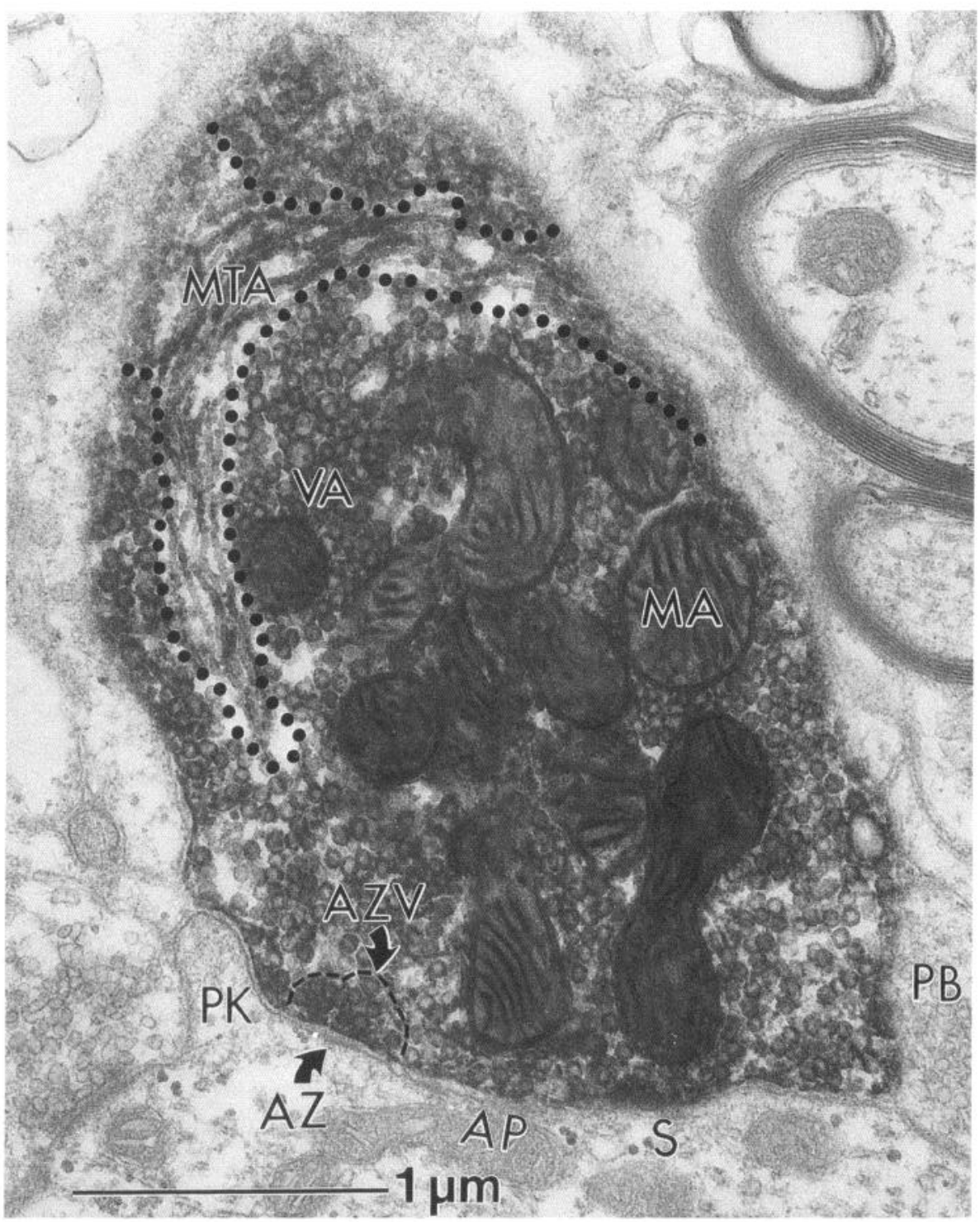

Figure 2. Ultrastructural features of a labeled Ia bouton and associated elements $(38,000 \times)$ that were used as a basis for quantification. Borders show the boundary between the vesicular area and the microtubule area, and circumscribe what were considered active zone vesicles. $V A$, vesicular area; $M T A$, microtubule area; $M A$, mitochondrial area; $A Z$, active zone; $A Z V$, active zone vesicles; $A P S$, apposed surface; $P K$, postsynaptic knob; $P B$, P bouton. tionships. Several boutons were also volume rendered using the Volvis system (Howard Hughes Institute of Medical Research and Dept. of Computer Sciences, SUNY-Stony Brook).

\section{Results}

\section{Fiber characteristics}

From the series of fibers injected in this study, three $(5,11$, and 16) were labeled well enough to permit full reconstruction of the parent axon and collaterals extending into the ventral horn. The fibers had conduction velocities ranging from 71 to 84 $\mathrm{m} / \mathrm{sec}$, and were very sensitive to direct stimulation of specific muscle belly locations.

In portions of the axonal arbor where boutons were serially reconstructed, the ultrastructure of the axonal branches was also examined. Most of these were sixth- to eighth-order branches, in a terminal part of the arbor. Axonal diameters ranged from 0.15 to $1.3 \mu \mathrm{m}$ (not including the thickness of the myelin wrap), and tended to taper as one moved downstream (although in one instance within a terminal en passant chain the diameter increased and the fiber remyelinated, downstream from several unmyelinated stretches; similar myelination patterns have been reported by Nicol and Walmsley, 1991). Myelinated portions were wrapped with from 9 to 10 turns of myelin. Fibers with diameters of $0.6 \mu \mathrm{m}$ or less were invariably unmyelinated. One first-order branch was also thin sectioned (diameter of $2.6 \mu \mathrm{m}$, 24 myelin turns).

\section{Bouton characteristics}

A. Form. Thirty-five boutons from various locations on these three fibers were fully reconstructed at the ultrastructural level.

Figure 1. Light-level reconstructions $(60 \times)$ of three collaterals on the three HRP-injected Ia afferent fibers, with insets $(260 \times)$ that identify the boutons on these collaterals that were reconstructed at the ultrastructural level (arrows point to the primary branch of each collateral). The arrangement of boutons on the three analyzed collateral sprigs is also shown in the insets. The fiber 11 sprig (boutons 11-1 to 11-10) represents a single Ia fibermotoneuron pairing, since all of the boutons contacted the base of the same dendrite. The micrographs $(29,000 \times)$ at the bottom are taken from the bouton identified by each arrow in the insets. $D$, dorsal; $R$, rostral; $A Z$, active zone. 

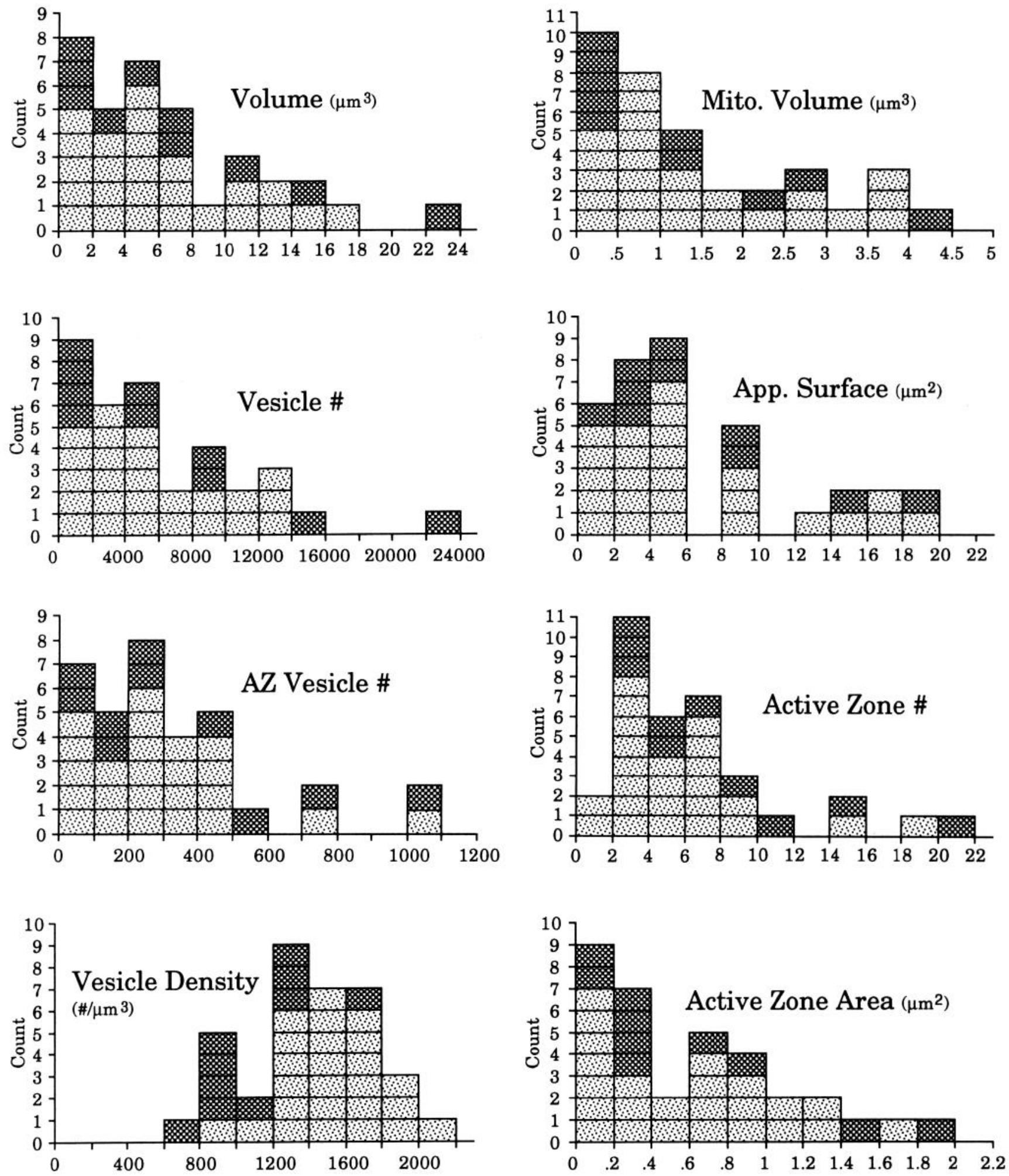

Figure 3. Distribution of the characteristics of boutons from a single Ia fiber-motoneuron pairing (boutons 11-1 to 11-10) compared to that of all other Ia boutons examined. This restricted group displayed almost as much variability as the entire population. Count in this and subsequent figures represents the number of boutons with particular values of the abscissa, which is labeled above the histogram for clarity. AZ, active zone. 


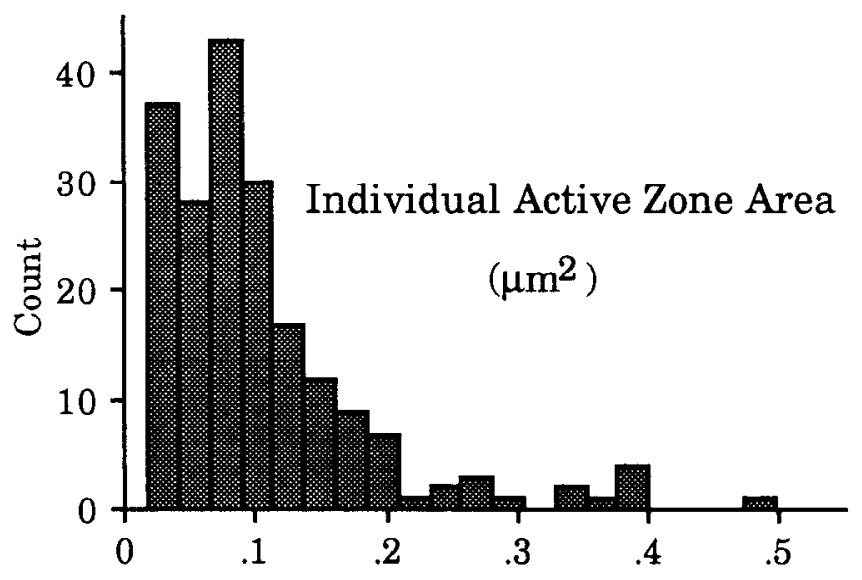

Figure 4. Distribution of the areas of 199 reconstructed individual active zones, displaying a heavy skew toward lower values (skewness of 2.06). Mean active zone area is $0.1 \mu \mathrm{m}^{2}\left[=0.6 \mu \mathrm{m}^{2}\right.$ (mean total $\mathrm{AZ}$ arca) $/ 6$ mcan active zones per bouton] (see Fig. 3).

Twenty-one were en passant boutons, 11 were terminal boutons, and 3 were located at branch points. The typical bouton had an ovoid shape, varying from 0.7 to $7.2 \mu \mathrm{m}$ along the long axis (usually parallel to the postsynaptic surface), and from 0.7 to $2.8 \mu \mathrm{m}$ along the short axis (usually perpendicular to the postsynaptic process). Bouton volumes ranged widely, from 0.45 to $22.4 \mu \mathrm{m}^{3}$ (mean of $6.5 \pm 5.4 \mu \mathrm{m}^{3}$ ), but the distribution was heavily skewed toward lower values, with $57 \%$ having volumes less than $6 \mu \mathrm{m}^{3}$ (skewness of 1.1). Additionally, bouton volume was related to position within the afferent arbor (see section F). The apposed surface was usually flattened and concave, giving many of them a "coffee bean" shape. Smaller boutons tended to be relatively round while larger boutons were more elliptical, extending primarily in one axis (as also observed by Nicol and Walmsley, 1991, for Clarke's column Ia boutons).

In the three instances where boutons were positioned between two postsynaptic elements (11-11, 16-2, and 16-9) this general form was altered. The boutons were apparently less rigid than the surrounding processes, and were flattened and compressed to fill the available space. Two boutons (11-11 and 16-8) also had cytoplasmic fingers that extended away from the bouton, either to recontact the same postsynaptic process or to contact an additional one.

B. Synaptic arrangement. Most of the boutons (85\%, 30 of $35)$ contacted only one postsynaptic element. In seven of these instances $(20 \%)$ the contact was directly on the soma, often near the base of a primary dendrite. The contacted cells had diameters ranging from $51 \times 37 \mu \mathrm{m}$ to $87 \times 47 \mu \mathrm{m}$, sizes consistent with an $\alpha$-motoneuron identification. 'The remaining contacts were on dendritic profiles that ranged in diameter from 0.6 to $8.4 \mu \mathrm{m}$, implying a widc distribution along dendritcs. Although the diameter of many of these dendrites strongly suggests that they are motoneuron processes, it should be noted that this cannot be directly demonstrated in this study (indeed, some of the smaller profiles might be interneuron processes).

In the three instances (9\%) where boutons were wedged between two postsynaptic elements, synaptic contacts were formed with both (which probably came from different cells, judging from differences in the plane of section). Additionally, two boutons $(6 \% ; 5-4,16-8)$ contacted three elements.

One group of 10 boutons on fiber $11(11-1$ to $11-10)$ all contacted the same motoneuron around the base of a large den-
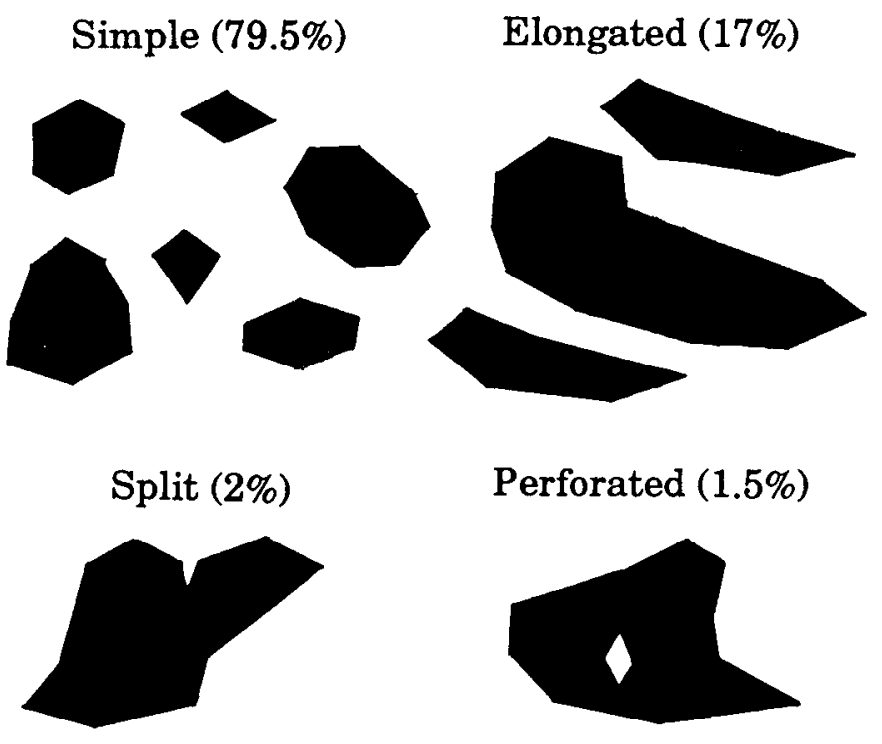

Perforated (1.5\%)

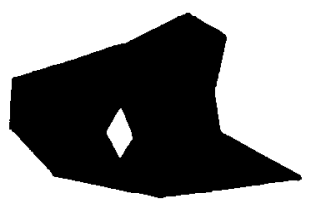

$1 \mu \mathrm{m}$

Figure 5. Reconstructions of active zones $(27,000 \times)$ which are representative of the four observed types of shape, with frequencies of occurrence.

drite. Thus, they comprised a single afferent-motoneuron pairing, which was a useful unit in which to examine the extent to which the identity of either the afferent or the motoneuron determined any given bouton characteristic. With the exclusion of vesicle density and average individual AZ size (not illustrated), bouton characteristics were almost as variable within this limited group as within the entire population (Fig. 3) (see Discussion, section 5).

As mentioned, small boutons corresponding to Conradi's typc $P$ class were commonly associated with labeled Ia boutons. Five Ia boutons (14\%) did not seem to be contacted by $\mathrm{P}$ boutons, eight $(23 \%)$ were associated with one, and $22(63 \%)$ were associated with more than one [5-9, a large bouton $\left(15.7 \mu \mathrm{m}^{3}\right)$, was associated with eight]. Of the $90 \mathrm{P}$ boutons observed, 59 (66\%) appeared to form triadic arrangements, being presynaptic to the postsynaptic element contacted by the labeled bouton. The Ia bouton surface area associated with $P$ boutons ( $P$ bouton surface) ranged from 0.18 to $6.6 \mu \mathrm{m}^{2}$ (mean of $1.5 \pm 1.5 \mu \mathrm{m}^{2}$ ), representing from $0.5 \%$ to $18.5 \%$ (mean of $6.9 \pm 5.2 \%$ ) of the total surface.

C. Synaptic surface. The apposed surface area ranged from 0.24 to $19.6 \mu \mathrm{m}^{2}$ (mean of $6.8 \pm 5.5 \mu \mathrm{m}^{2}$ ), which represented from 12.1 to $45.5 \%$ of the total surface (mean of $31.8 \pm 8.3 \%$ ). Four boutons had a gap in the center of their apposed surface (up to $0.18 \mu \mathrm{m}$ wide), and in eight others small postsynaptic knobs $(0.2-0.4 \mu \mathrm{m}$ wide and $0.3-0.7 \mu \mathrm{m}$ long) either invaginated the bouton or abutted one side of it (these knobs were often associated with active zones).

From 1 to 21 (mean of $6.1 \pm 4.8$ ) distinct active zones of various sizes and shapes were located on the apposed surface of each bouton. Individual $\mathrm{AZ}$ size ranged from 0.02 to 0.50 $\mu \mathrm{m}^{2}$ (mean of $0.10 \pm 0.08 \mu \mathrm{m}^{2}$ ), and was heavily skewed toward lower values (skewness of 2.06) (Fig. 4). Of the 199 reconstructed active zones, the majority $(79.5 \%)$ had simple, relatively symmetrical shapes, while $17 \%$ were elongated, $2 \%$ were partially split, and $1.5 \%$ were perforated (Fig. 5). The average individual 


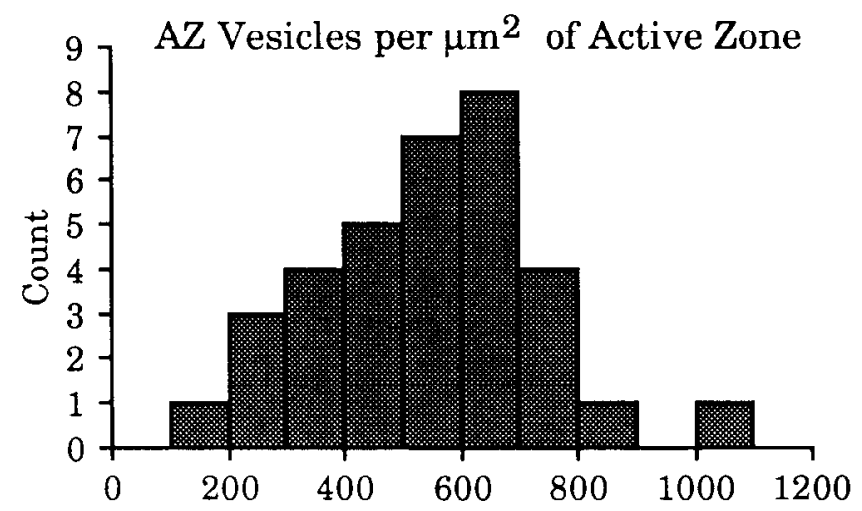

Figure 6. Distribution of $\mathrm{AZ}$ vesicles per $\mu \mathrm{m}^{2}$ of active zone. On average there are $545 \mathrm{AZ}$ vesicles per $\mu \mathrm{m}^{2}$ which, when one considers that there is on average $0.1 \mu \mathrm{m}^{2}$ per active zone (see Fig. 4), yields about 56 $A Z$ vesicles per active zone on average.

$A Z$ size for a given bouton (average individual $A Z$ size) varied from 0.05 to $0.31 \mu \mathrm{m}^{2}$ (mean of $0.11 \pm 0.06 \mu \mathrm{m}^{2}$ ), while total $\mathrm{AZ}$ area for a given bouton ranged from 0.05 to $1.8 \mu \mathrm{m}^{2}$ (mean of $0.62 \pm 0.05 \mu \mathrm{m}^{2}$ ). The percentage of the apposed surface occupied by active zones (AZ percentage apposed surface) also varied widely, from $1.8 \%$ to $75.5 \%$ (mean of $12 \pm 13 \%$ ).

D. Internal structure. The cytoplasm of each bouton was divided into two relatively distinct regions (see Materials and Methods). Portions of the bouton that contained microtubules only very rarely contained more than a few vesicles. These microtubules usually extended into the bouton from the point of axon entry, and in en passant arrangements passed fully through each bouton, forming a kind of "backbone." In contrast, the areas closer to the apposed surface, where high densities of vesicles were found, never contained any microtubules. Within these areas vesicles were relatively evenly distributed, except for the small, tight clusters of $\mathrm{AZ}$ vesicles. Vesicle number per bouton ranged widely, from 313 to 22,900 vesicles (mean of $5900 \pm 5200$ vesicles). As with volume, the distribution was heavily skewed toward lower values, with $60 \%$ containing fewer than 6000 vesicles (skewness of 1.2). The vesicle density within nonmicrotubule regions ranged from 741 to 2060 vesicles $/ \mu \mathrm{m}^{3}$ (mean of $1400 \pm 330$ vesicles $/ \mu \mathrm{m}^{3}$ ). Vesicle density as a function of total bouton volume ranged from 400 to 1290 vesicles $/ \mu \mathrm{m}^{3}$ (mean of $870 \pm 260$ vesicles $/ \mu \mathrm{m}^{3}$ ), while vesicle density as a function of total cytosolic volume ranged from 526 to 1570 vesicles $/ \mu \mathrm{m}^{3}$ (mean of $1110 \pm 330$ vesicles $/ \mu \mathrm{m}^{3}$ ).

$\mathrm{AZ}$ vesicle number varied from 26 to $1100 \mathrm{~A} Z$ vesicles (mean of $320 \pm 270 \mathrm{AZ}$ vesicles) and, as with vesicle number, was skewed toward lower values (skewness of 1.39). This closcly apposed pool of vesicles represented from $1.6 \%$ to $29.5 \%$ of the vesicle number (mean of $7.4 \pm 5.2 \%$ ). The number of $A Z$ vesicles normalized to the $\mathrm{AZ}$ area ranged from 161 to $1090 \mathrm{AZ}$ vesicles $/ \mu \mathrm{m}^{2} \mathrm{AZ}$ (mean of $545 \pm 190 \mathrm{AZ}$ vesicles $/ \mu \mathrm{m}^{2} \mathrm{AZ}$ ) (Fig. $6)$. The average number of $A Z$ vesicles per active zone (AZ vesicles/AZ) varied from 24 to 223 (mean of $56 \pm 37 \mathrm{AZ}$ vesicles/AZ).

Mitochondria were found in both vesicle and microtubule regions, though usually not directly adjacent to active zone sites. Mitochondrial volume ranged from 0.04 to $4.26 \mu \mathrm{m}^{3}$ (mean of $1.42 \pm 1.20 \mu \mathrm{m}^{3}$ ), while percentage mitochondrial volume varied from $6.5 \%$ to $39 \%$ (mean of $21.3 \pm 7.7 \%$ ).

$E$. Interrelationships. In the present study, Ia bouton apposed surface area, $A Z$ number, total $A Z$ area, vesicle number, $A Z$ vesicle number, and mitochondrial volume were all linearly related to bouton volume in a positive manner, with relatively high correlation coefficients $(r=0.94$ for vesicle number, $r=$ 0.94 for mitochondrial volume, $r=0.89$ for $\mathrm{AZ}$ number, $r=$ 0.87 for total $\mathrm{AZ}$ area, $r=0.86$ for $\mathrm{AZ}$ vesicle number, and $r$ $=0.83$ for apposed surface area) (Fig. 7). Thus, as the volume of a bouton increases, all of these organelles are added in direct proportion. This is surprising since one would expect surface features (such as apposed surface area, $\mathrm{AZ}$ number, and total $A Z$ area) to increase as a square of radius while volume increases as a cube. However, this relationship does not hold for Ia boutons: volume and surface area are also linearly related $(r=0.92)$. A consideration of bouton shape could explain this. Increasing bouton size might be analogous to lengthening a cylinder: volume and surface area are added in direct proportion, along an axis. Such strong coincident correlations imply strong crosscorrelations, which were observed. For example, AZ vesicle number was correlated with A7. number $(r=0.96)$, total A7. area $(r=0.92)$, and vesicle number $(r=0.86)$.

These scaling relationships also extended to the synaptic arrangements in which labeled Ia boutons were involved. Both $P$ bouton number and $\mathrm{P}$ bouton surface were correlated with Ia bouton volume ( $r=0.82$ and $r=0.80$, respectively). Similarly, factors that presumably reflect the strength of synaptic interactions and that were associated with Ia bouton volume also displayed cross-correlations. AZ number was correlated with $\mathrm{P}$ bouton number $(r=0.63)$ and total $\mathrm{AZ}$ area was correlated with $\mathrm{P}$ bouton surface $(r=0.69)$. All of these relationships were significant at the $p<0.0001$ level (Fisher's $r$-to- $z$ transformation).

F. Positional relationships. The characteristics of each bouton were also examined in relation to their position: on the postsynaptic element, within the terminal field, and in the presynaptic arbor.

As mentioned, Ia boutons contacted profiles of highly variable size, suggesting a wide distribution. Correlating bouton characteristics with the diameter of the postsynaptic process, two types of relationships became apparent. First, large Ia boutons were restricted to large-diameter profiles $(>4 \mu \mathrm{m})$, while smaller boutons could be found on profiles of any diameter. This distribution pattern was evident in terms of bouton volume, $\mathrm{AZ}$ number (not illustrated), total AZ area (not illustrated), and $P$ bouton surface, the portion restricted to large-diameter profiles representing the upper half of the characteristic's range [from 13 to $22.5 \mu \mathrm{m}^{3}$ for volume, 9 to 21 for $\mathrm{AZ}$ number, 1.2 to 1.8 $\mu \mathrm{m}^{2}$ for total $\mathrm{AZ}$ area, and 3 to $6.6 \mu \mathrm{m}^{2}$ for $\mathrm{P}$ bouton surface (which, since $\mathrm{P}$ bouton number did not fit such a relationship, suggests that the largest $P$ boutons are associated with Ia boutons that contact large-diameter profiles)] (Fig. 8A). Second, several bouton features were directly correlated with profile diameter. As profile diameter decreased, both apposed surface area (not illustrated) and percentage apposed surface decreased $(r=0.39$, $p=0.01$; and $r=0.56, p<0.0001$, respectively) (Fig. 8B), while average individual $A Z$ size, percentage mitochondrial volume, and vesicle density all increased $(r=-0.51, p=0.0006$; $r=-0.51, p=0.0005$; and $r=-0.38, p=0.01$, respectively) (Fig. $8 C$ ). The distribution of average individual $A Z$ size could in part be related to fiber differences. Average individual $A Z$ size was the only bouton characteristic that was significantly fiber specific ( $p<0.001$, nested ANOVA), and while fiber 11, with the smallest average individual $A Z$ sizes, tended to ter- 

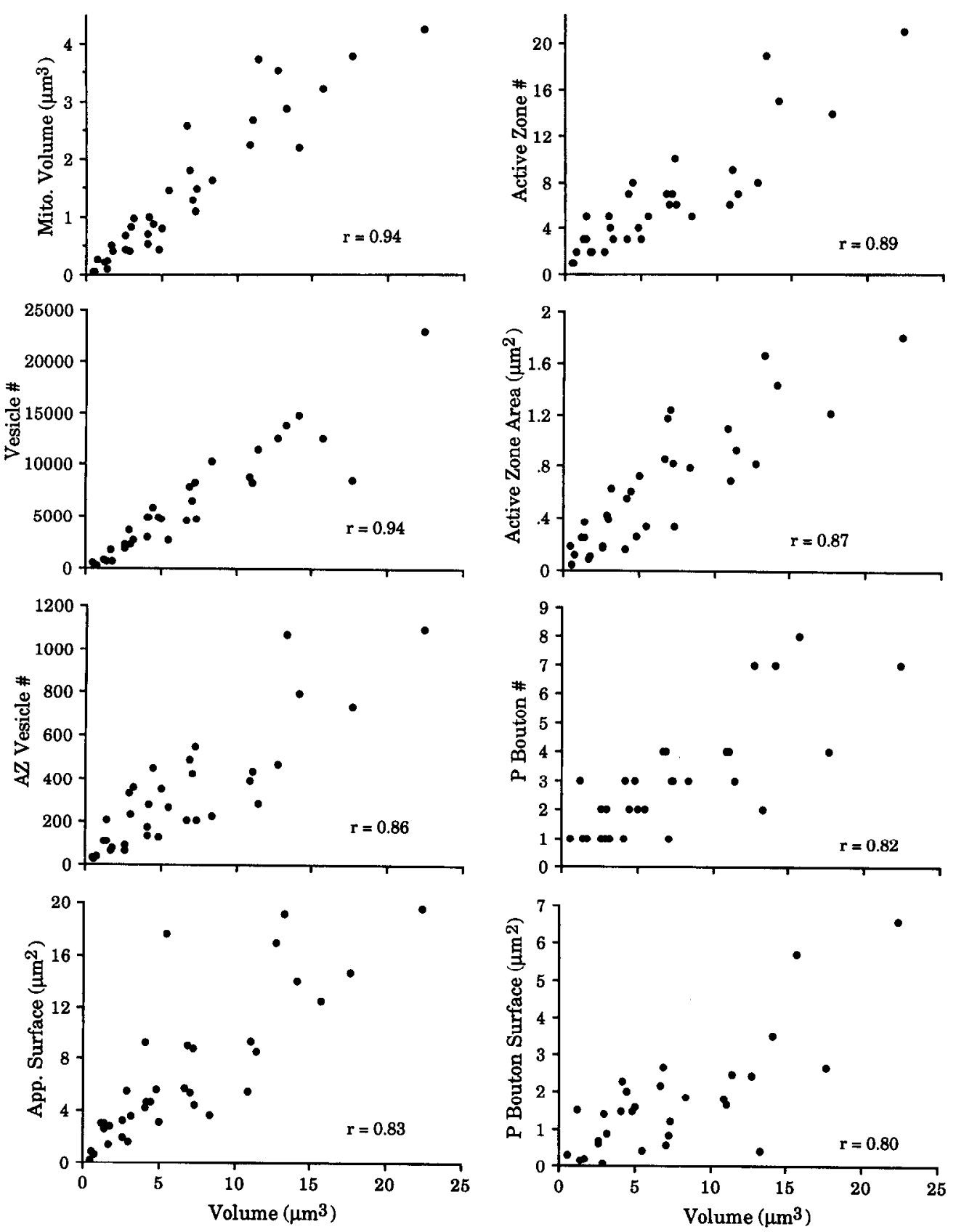

Figure 7. Mitochondrial volume, vesicle number, $A Z$ vesicle number, apposed surface, active zone number, active zone area, $\mathrm{P}$ bouton number, and $P$ bouton surface were all highly correlated with la bouton volume, suggesting that these characteristics scale directly with bouton size $(p<0.0001$ for all correlations)

minate on large diameter profiles $(>2.5 \mu \mathrm{m})$, fiber 16 , with the largest average individual $\mathrm{AZ}$ sizes, tended to terminate on relatively smaller diameter profiles $(<5.3 \mu \mathrm{m})$.

Since the DRE zone could be identified for all three fibers, it was possible to test whether bouton features varied within the terminal field, as one moved away from this location. The boutons of fiber 11 came from either under the DRE zone, or a position $1.9 \mathrm{~mm}$ rostral to it (the rostral boutons were $11-1$ to 11-10, which comprised a single afferent-motoneuron pairing). When DRE zone boutons were compared with "distant" boutons for fiber 11 , a significant difference in vesicle density was observed ( $p<0.03, t$ test), with the distant boutons having lower densities $\left(1086 \pm 275\right.$ vesicles $\left./ \mu \mathrm{m}^{3}\right)$ than the DRE zone boutons $\left(1418 \pm 300 \mathrm{vcsiclcs} / \mu \mathrm{m}^{3}\right)$. This finding may be limited by the fact that all the distant boutons contacted the same motoneuron, since this group showed a smaller range of vesicle densities than the entire population (Fig. 3). The boutons of fibers 5 and 16 were all located almost directly under the DRE zone, and had vesicle densities comparable to the fiber 11 boutons in that position $\left(1573 \pm 230\right.$ vesicles $/ \mu \mathrm{m}^{3}$ for fiber 5 and 16 boutons).

The morphological characteristics of each bouton were also related to its position within the afferent arbor. On terminal branches (including branch point boutons), as one moved downstream, bouton volume and associated characteristics tended to decrease (or stay the same), with the exception of the terminal bouton, which could have either the highest or lowest value (Fig. 9A). Although there were exceptions (marked with dots), the pattern was apparent, with volume, apposed surface area, and $\mathrm{AZ}$ number showing the strongest relationships, followed by vesicle number and surface area (not illustrated). Additionally, the extent of $\mathrm{P}$ bouton association also appeared to be 
Figure 8. Ia bouton characteristics were related to the diameter of the postsynaptic process in two manners. First, boutons in the upper half of the range of volumes (or volume associated features, like $\mathrm{P}$ bouton surface) were limited to large-diameter processes, while smaller boutons could be found on processes of any size $(A)$. Second, the percentage of the bouton surface apposed to the process was positively correlated with the diameter of the process $(p<$ $0.0001)(B)$, while average individual $\mathrm{AZ}$ area, percentage mitochondrial volume, and vesicle density were negatively correlated with the diameter of the process $(p=0.0006, p=0.0005$, and $p=0.01$, respectively) $(C)$.
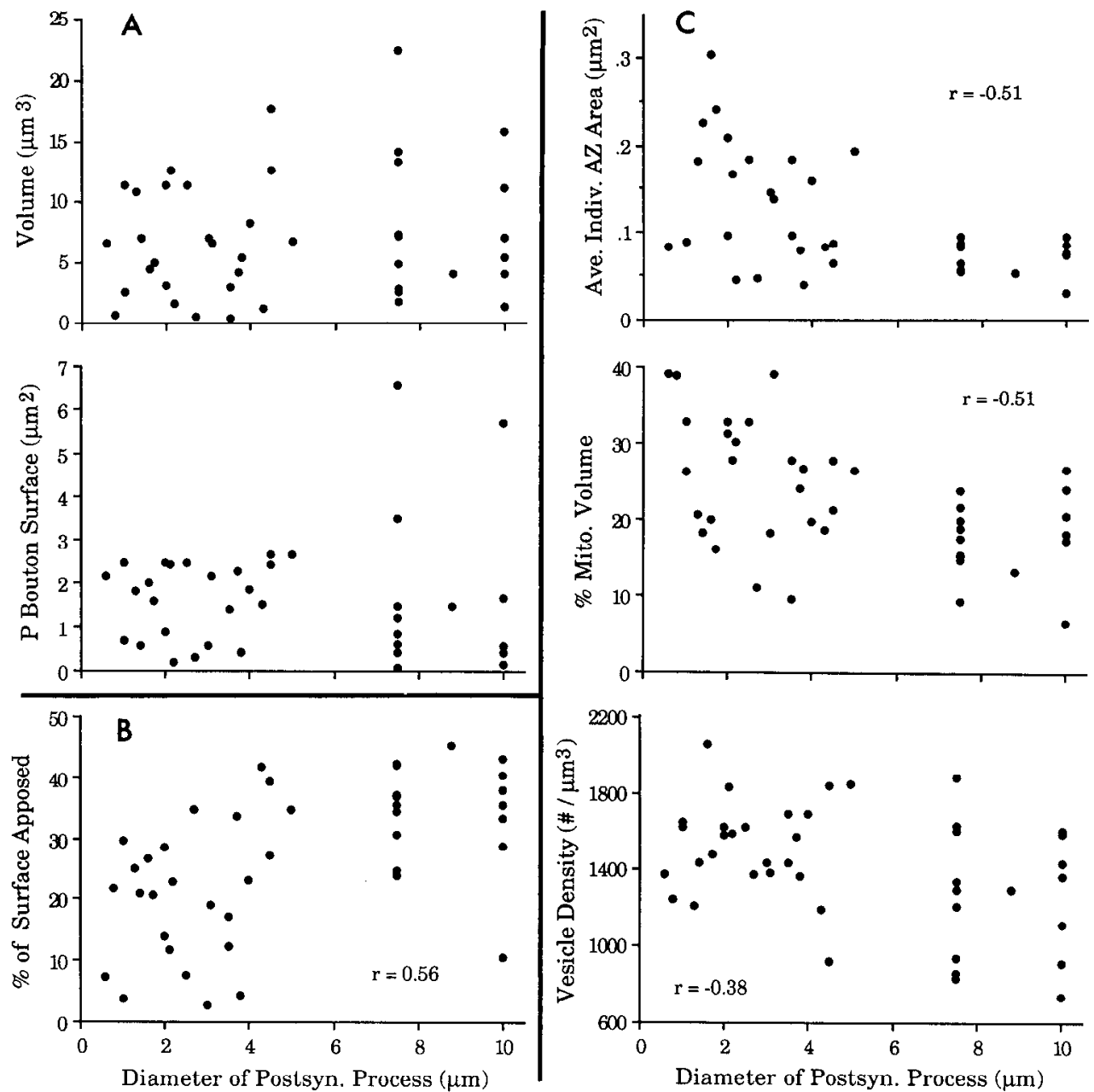

related to the arbor position of the Ia bouton: both $\mathrm{P}$ bouton number and $P$ bouton surface (not illustrated) decreased as volume did, moving downstream. One characteristic, $A Z$ vesicle percentage, ran counter to the general pattern, displaying a significant increase as one moved downstream (Fig. 9B).

\section{Discussion}

Conradi (1969) developed the standard ultrastructural classification scheme for contacts on motoneurons, subdividing them on the basis of bouton size, vesicular shape, width of the cleft and postsynaptic thickening, and associations with specialized postsynaptic structures (dense bodies and subsynaptic cisterna). With the use of intra-axonal HRP labeling, Conradi et al. (1983) and Fyffe and Light (1984) later identified Ia afferent terminals as Conradi's type S ending, with which our findings are in general agreement. This bouton class was characterized as being small to medium sized $(0.5-4.0 \mu \mathrm{m}$ long), with round vesicles, a wide cleft, a thin postsynaptic thickening, and no association with dense bodies or cisterna. These endings were often associated with postsynaptic knobs, which either formed a palisade on one side or directly extended into it. Group Ia afferent boutons were similarly examined in other terminal regions: lamina VI (Maxwell and Bannatyne, 1983; Fyffe and Light, 1984) and Clarke's column (Walmsley et al., 1985; Nicol and Walmsley, 1991). In general, these contacts were quite similar in form, with the exception that in Clarke's column some were associated with dense bodies (resembling Conradi's $\mathbf{M}$ type) and others were extremely large ("giants," up to $20 \mu \mathrm{m}$ long).

However, the extent of variation in the size and form of the presently described Ia bouton profiles would have at times made their classification on the basis of ultrastructural form alone difficult, especially when judged from an individual section. Nicol and Walmsley (1991) have described a similar degree of size variability in the boutons of a single Ia afferent collateral terminating in Clarke's column. Indeed, in describing our labeled, identified terminals, it was the wide variation, across virtually all of the ultrastructural features examined, that stood out. This variability, along with the fact that, for a given bouton, features associated with synaptic release (such as vesicle number, $A Z$ vesicle number, $A Z$ number, and total $A Z$ area) were strongly correlated, supports physiological indications (Jack et al., 1981a; Walmsley et al., 1988) of wide variability in the synaptic efficacy of individual boutons. This variation was observed both across the whole population studied and within the boutons of a single afferent-motoneuron pairing (boutons 11-1 to 11-10) (Fig. 3).

\section{Vesicle density, number, and distribution}

The mean density of vesicles within the nonmicrotubule regions (1400 vesicles $/ \mu \mathrm{m}^{3}$ ) is similar to that reported by Yeow and Peterson (1991) for unlabeled contacts on turtle motoneurons (1132 vesicles $\left./ \mu \mathrm{m}^{3}\right)$. Bouton vesicle densities have been re- 

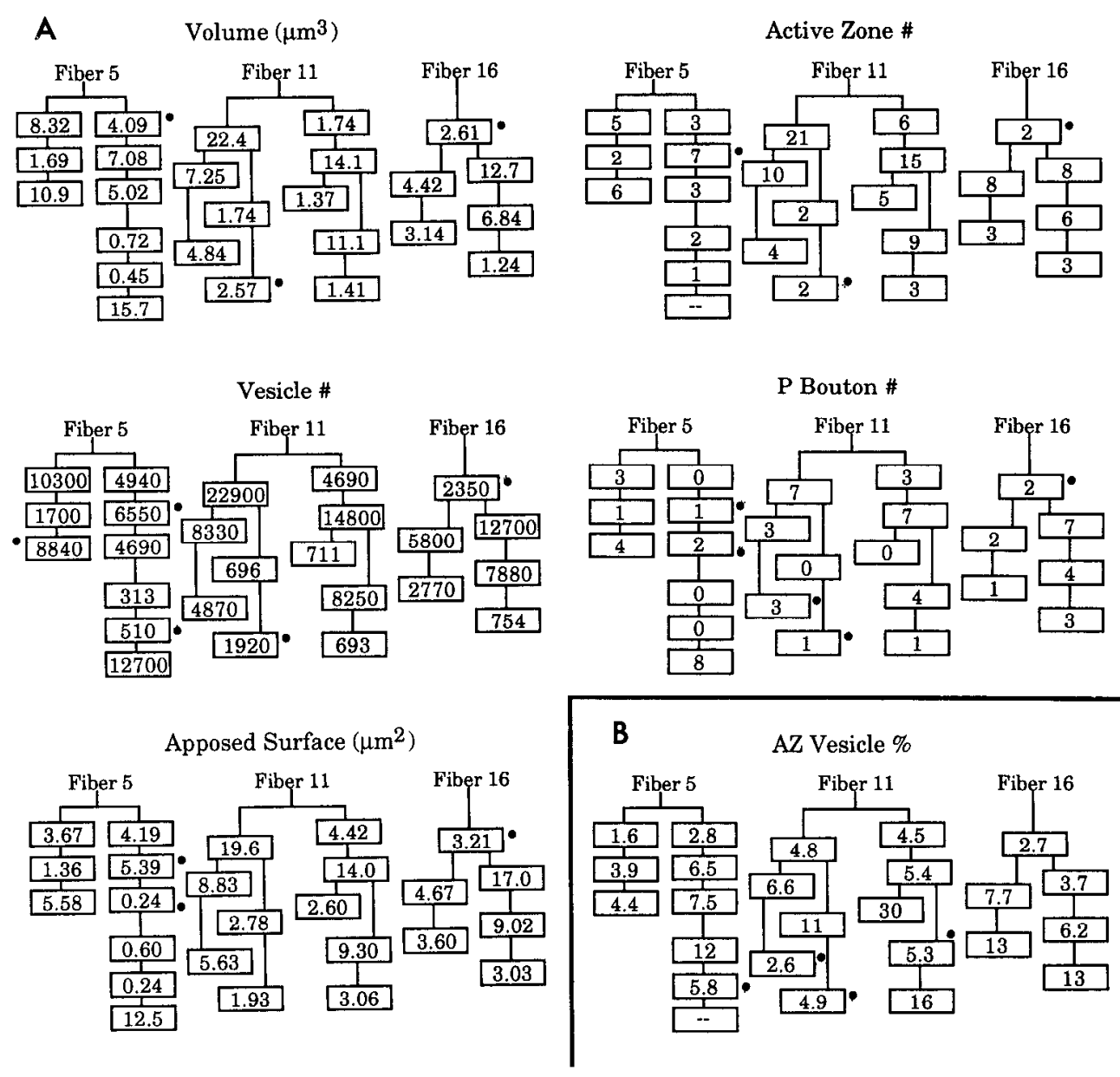

- Exceptions
Figure 9. Ia bouton characteristics reflected the bouton's position within the afferent arbor. The three terminal arbor sprigs reconstructed in Figure 1 are schematized, with the given characteristic listed at each bouton position. As one moves downstream within a terminal branch (including branch point boutons), volume related features (vesicle number, apposed surface, active zone number, and $\mathrm{P}$ bouton number) tended to decrease (or stay the same), until the terminal bouton, which could have either the highest or lowest value on the branch $(4)$. AZ vesicle percentage ran counter to this general pattern, increasing as one moves downstream $(B)$. Exceptions to the pattern are marked with dots. ported for other fiber types (usually expressed as densities in the plane of section, and extrapolated to a volume density estimate; Floderus, 1944). Some identified fiber types (climbing and parallel fibers; Palay and Chan-Palay, 1974; Hillman and Chen, 1985) have boutons with uniform vesicle densities, while others (Ia afferents and chandelier cell axons; Peters and Harriman, 1990) have boutons that contain widely variable vesicle densitics.

Vesicle density has been suggested as a criterion for the classification of unlabeled boutons. Rose and Neuber-Hess (1991) have recently presented a classification scheme for contacts on neck motoneurons based on vesicle shape, distribution pattern, and density. However, the wide variability in vesicle density observed among some fiber types casts doubt on the usefulness of this form of classification. Using the subdivisions of Rose and Neuber-Hess (1991), the vesicle densities of the Ia terminals on a single labeled fiber in the present study (741-2060 vesicles/ $\left.\mu \mathrm{m}^{3}\right)$ stretch across large portions of two of their three vesicle density groups. In the case of Ia boutons, this wide variability might reflect systematic differences that relate to the position of the bouton on the postsynaptic element (see section 6) and within the terminal field (see section 7). The total number of vesicles contained within each Ia bouton also varied greatly, with a heavy skew toward lower values. This is similar to what has been reported in the cerebellar and hippocampal studies of Harris and Stevens $(1988,1989)$ and the ventral horn studies of Yeow and Peterson (1991), although the range of values for Ia boutons is much greater.

Without being able to estimate the rate of vesicle turnover or supply, it is still intriguing to consider that fibers that can fire at rates of up to $500 \mathrm{~Hz}$ (Prochazka et al., 1976) have boutons whose vesicle numbers are highly skewed toward low values. Vesicle depletion might play a role in the changes in amplitude obscrved during high-frequency stimulation at Ia synapses on motoneurons (Collins et al., 1984). Following the application of conditioning stimuli to perforant path fibers, Fifková and Van Harreveld (1977) observed a decrease in the vesicle density of perforant path terminations on dentate granule cells.

The distinctive distribution of the vesicles that were tightly clustered against active zones suggested that they should be considered as a discrete subgroup of the total population. It is known that vesicles near active zones are bound by synapsin I cross-linkages to a filamentous actin network that extends from the active zones (Ueda and Greengard, 1977). This implies that they represent a readily accessible pool of vesicles, whose relative size might change with levels of activity and affect the probability of release. At the same connection in which Fifková and Van Harreveld (1977) observed decreases in overall vesicle density with conditioning, Desmond and Levy (1986) have reported an associated increase in the number of "front-line" vesicles. The induction of LTP in CAl has been correlated with increases in the $A Z$ vesicle percentage (Applegate et al., 1987). 
Apposed Area

Active Zones
Presynaptic Contacts ( $\mathrm{P}$ boutons)

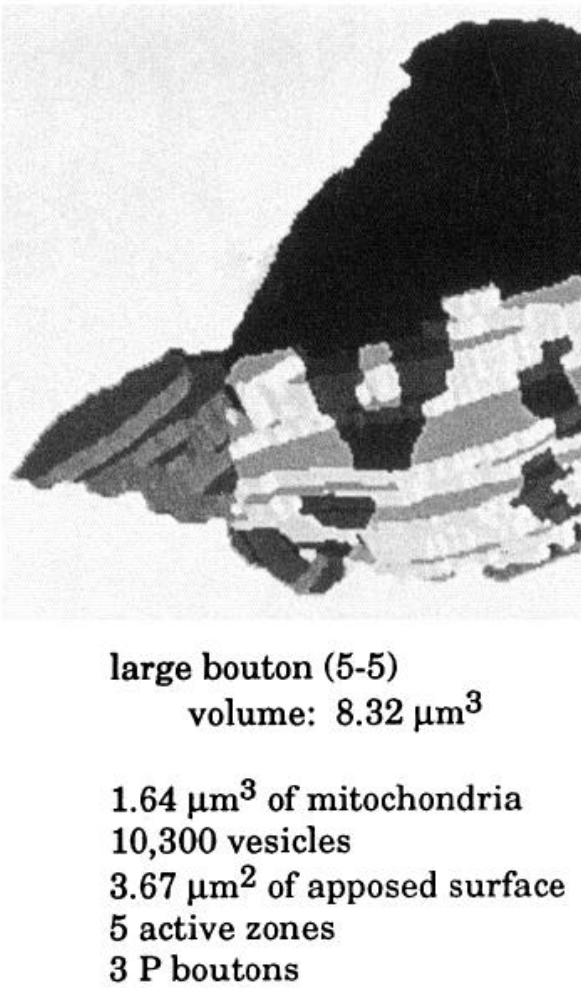

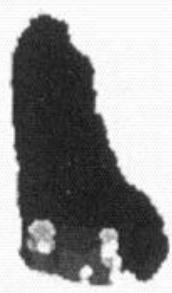

small bouton (5-7) volume: $0.45 \mu \mathrm{m}^{3}$

Three-dimensional reconstructions of two Ia boutons (5-5 and $5-7$ ) on the fiber 5 sprig (see Figs. 1, 9) generated with the Volvis system, showing their surfaces of apposition, active zones, and associated $P$ boutons. Mitochondrial volume, vesicle number, apposed surface area, active zone number, and $\mathrm{P}$ bouton number all scale with volume (see Fig. 7). greater range of $\mathrm{AZ}$ number (1-21, mean of 6.1), total $\mathrm{AZ}$ area $\left(0.05-1.80 \mu \mathrm{m}^{2}\right.$, mean of $\left.0.62 \mu \mathrm{m}^{2}\right)$, and $\mathrm{AZ}$ percentage apposed surface $(1.8-75.5 \%$, mean of $12 \%)$ than has been previously reported in this and other systems, implying that Ia boutons have a potentially wider range of synaptic efficacies. The range of AZ sizes $\left(0.02-0.50 \mu \mathrm{m}^{2}\right.$, mean of $\left.0.10 \mu \mathrm{m}^{2}\right)$ was smaller than that found for unidentified motoneuron contacts (Yeow and Peterson, 1991; Antal et al., 1992), although greater than reported for contacts in other brain regions (Streichert and Sargent, 1989, cardiac ganglion cell terminals; Peters and Harriman, 1990, symmetric synapses on cortical pyramidal cells; Harris and Stevens, 1988, 1989, cerebellar parallel fiber boutons and contacts on CA1 pyramidal spines).

Determining morphological correlates of $n$ and $p$ at these synapses has been a major focus of research and debate. Several groups (Jack et al., 1981a; Neale et al., 1983; Redman and Walmsley, 1983; Pun et al., 1986) have argued, from estimates of $n$ and light-level bouton counts, that each bouton represents one release site. Considering that most of the boutons studied here contain multiple active zones (see also Fyffe and Light, 1984; Walmsley et al., 1985), this would require cooperative behavior between isolated release sites in a bouton. Present evidence does not support cooperativity (see discussion in Walmsley et al., 1988). If it were to occur partially, the action of individual release sites would not be independent and the EPSP amplitude distribution could not be modeled by a compound binomial process (Jack et al., 1981a). Thus, it seems likely that $n$ is equal to the number of active zones. Since the average bouton has six active zones contacting the same motoneuron, and quantal size averages about $100 \mu \mathrm{V}$ (Kuno, 1964; Jack et

\section{Active zone area, form, and number}

AZ size and number have been more directly associated with synaptic strength than vesicle density or number (see introductory remarks). In the present study, Ia boutons had a much 
al., 1981a), $p$ for many of these sites must be at or near 0 . Since $p$ has been correlated with AZ size (as demonstrated at the $\mathrm{NMJ}$; Govind and Chiang, 1979; Atwood and Marin, 1983; Propst and $\mathrm{Ko}, 1987$ ), the skew of $\mathrm{AZ}$ areas toward lower values in the present study (Fig. 4) would seem to support this. An alternative interpretation, suggested by the conclusion of Clamann et al. (1991), that some quantal units are significantly smaller than $100 \mu \mathrm{V}$ would require higher $p$ values with fewer silent release sites. Support for the contention that normally "silent" release sites do exist comes from sludies of changes in amplitude fluctuations of EPSPs augmented during posttetanic potentiation (Hirst et al., 1981) and after systemic administration of 4-aminopyridine (Jack et al., 1981b), along with comparisons between calculated values for $n$ and light-level bouton counts (Redman and Walmsley, 1983). Clamann et al. (1989) suggested that only $15 \%$ of Ia boutons release transmitter in response to an action potential before posttetanic potentiation. All these considerations support the use of the compound binomial distribution, with $p=0$ at some release sites, to describc transmitter release at the Ia-motoneuron connection (Redman, 1990).

\section{Bouton size as a measure of potential efficacy}

Although the ultrastructural features examined in this study were widely variable, many of them, including apposed surface area, $A Z$ number and total $A Z$ area, vesicle and $A Z$ vesicle number, and mitochondrial volume, correlated strongly with Ia bouton size in a positive, linear manner (Fig. 7). All of these factors displayed a similar degree of variability, with a skew toward lower values.

Related types of size associations have been previously reported. Hamos et al. (1987) revealed that although boutons arising from a single retinogeniculate axon varied considerably in size, $\mathrm{AZ}$ number correlated well with bouton volume. Harris and Stevens $(1988,1989)$ found that vesiclc numbcr, $A Z$ area, and spine head volume were correlated among contacts of parallel fibers on Purkinje cell spines, while among contacts on hippocampal pyramidal cell spines, bouton volume, vesicle number, $\mathrm{AZ}$ area, and spine volume were correlated. Streichert and Sargent (1989) observed a correlation between apposed surface area and both $\mathrm{AZ}$ number and area in contacts on frog cardiac ganglion neurons. In symmetric terminals on cortical pyramidal cells Peters and Harriman (1990) found the same association. Within their mixed population of terminals on turtle motoneurons, Yeow and Peterson (1991) described a scaling relationship between apposed surface area, AZ number and area, and vesicle number and bouton volume. Mitochondrial volume has not been previously examined in this context, although Vaughn and Grieshaber (1972) observed that unidentified terminals in adult rat spinal cord had on average $22 \%$ of their volume occupied by mitochondria, a value that is very close to our average of $21 \%$.

The observation that mitochondrial volume, vesicle and AZ, vesicle number, and $A Z$ number and area are all correlated with bouton volume in the same linear fashion implies that a relatively constant ratio is maintained between energy-supplying organelles, available transmitter and release site surfaces across a wide range of bouton sizes (Fig. 10). On average, every $1 \mu \mathrm{m}^{3}$ of bouton volume is associated with $0.21 \mu \mathrm{m}^{3}$ of mitochondria, 900 vesicles, $50 \mathrm{AZ}$ vesicles, and 0.9 active zones of $0.12 \mu \mathrm{m}^{2}$. The fact that the wide variation in vesicle density does not affect this relationship suggests that variations in vesicle density reflect differences in the size of the vesicular region to which vesicles are restricted.

If one then assumes that $A Z$ number, $A Z$ area, number, vesicle and $A Z$ vesicle number are in some manner associated with synaptic strength, then bouton size would seem to be a good measure of potential synaptic efficacy. Synaptic efficacy could be adjusted by changing bouton size. Hillman and Chen (1985) have reported that, when they lesioned roughly $50 \%$ of a parallel fiber tract, the remaining contacts on Purkinje cell spines increased in size to compensate for the loss of synaptic input, with no concurrent change in vesicle density. There is also evidence indicating that vesicle and active zone characteristics could bc coregulated. Han et al. (1991) increased synapsin IIb levels by transfection in a neuronal cell line (NG108-15) and found a concomitant dramatic increase in vesicle number and the induction of active zone formation.

These correlations suggest an ultrastructural "size principle," which would posit that morphological features associated with synaptic release (such as vesicle number, $A Z$ number and area, and mitochondrial volume) scale in a direct linear fashion with bouton volume. This pattern of scaling also seems to extend beyond the features of individual boutons to encompass the local synaptic arrangements in which they are involved. Both $P$ bouton number and surface are closely correlated with the size of the boutons they contact.

\section{Presynaptic contacts}

Ia boutons in our study received relatively high levels of presynaptic input $(86 \%$ were associated with from one to eight $P$ boutons). In agreement with Fyffe and Light (1984), many $P$ boutons $(66 \%)$ formed triadic arrangements by contacting both Ia boutons and their target dendrites. Maxwell et al. (1990) have recently demonstrated that $P$ boutons in lamina VI are immunoreactive for GABA, and Peng and Frank (1989a,b) have shown that $\mathrm{GABA}_{\mathrm{A}}$ and $\mathrm{GABA} \mathrm{B}_{\mathrm{B}}$ receptors mediate presynaptic inhibition at the frog Ia-motoneuron synapse, strongly suggesting that $P$ boutons are the source of this type of inhibition.

Ia boutons that were not contacted by $\mathrm{P}$ boutons were all quite small, while the boutons associated with the greatest number were all quite large (see also Conradi et al., 1983), in agreement with the size principle detailed in the previous section. Such a relationship could develop out of local, relatively nonselective mechanisms. This would scale the strength of presynaptic inhibition with the potential synaptic efficacy of the bouton, since factors like $\mathrm{AZ}$ number and $\mathrm{AZ}$ vesicle number are also strongly determined by the size principle. Tse et al. (1991) have reported this type of synaptic scaling relationship at the crab NMJ, where those producing large EPSPs were associated with both more inhibitory axoaxonal contacts, and stronger levels of presynaptic inhibition.

This is not to imply that this relatively nonselective pattern of association could not exert selective inhibitory effects on afferent arbors. Branch point boutons were often very large and were thus associated with many $P$ boutons, which could block action potentials from invading all of the boutons downstream. It also remains to be determined if selective contacts from different sources of presynaptic inhibition could be hidden by this general pattern (Rudomin, 1990).

\section{Variability within a single Ia-motoneuron pairing}

The Ia-motoneuron projection is a particularly good system in which to examine the question of synaptic specialization. Each 
afferent fiber is thought to contact virtually all homonymous motoneurons (Mendell and Henneman, 1971). The extent of EPSP facilitation or depression produced when Ia afferents are stimulated at high frequency is correlated with the characteristics of the motoneuron (Collins et al., 1984). These differences in response properties are expressed at the level of an individual fiber's contacts onto different motoneuron types (Koerber and Mendell, 1991), indicating that the motoneuron is determining synaptic properties. If, as it has been suggested (Kuno, 1964), the mechanisms subserving the response properties are presynaptic, then one might be able to identify ultrastructural bouton characteristics that are related to the type of motoneuron contacted. Alternatively, since all the terminals of a single fiber share the same genetic information, there might be fiber specific bouton characteristics.

To explore the extent of synaptic specialization, one can compare variability within the boutons of a single Ia afferent-motoneuron pairing to variability within the entire population. If any of the morphological characteristics examined is strongly determined by the identity of either the afferent or motoneuron, then boutons in the single pairing should exhibit much less variability than the full population. The 10 boutons of fiber 11 (boutons $11-1$ to $11-10$ ) represented just such a pairing. Within this subpopulation, the extent of variation for most characteristics examined was nearly as great as the extent of variation for the entire population (Fig. 3). However, average individual AZ size proved to be significantly fiber specific as measured by a nested ANOVA, which was perhaps related to differences in the level of fiber activity. This suggests that the morphological features of individual Ia boutons are not influenced primarily by the identity of either the associated afferent or motoneuron. Motoneuron-related differences in EPSP response patterns would have to be related to either other synaptic features (postsynaptic properties or presynaptic differences in cytoplasmic constituents and/or receptor and channel distributions), or characteristics of the group of boutons involved in a single Ia-motoneuron pairing, such as selective activation (through either incomplete action potential invasion or selective presynaptic inhibition).

\section{Bouton distribution on the postsynaptic element}

The extensive nature of motoneuron dendrites has prompted the search for selective distributions of motoneuron contacts. While Conradi (1969), Kellerth et al. (1979, 1983), and Brännström (1993) reported that type-S boutons were positioned predominantly distally on dendrites, Conradi et al. (1983) and Fyffe and Light (1984) found that labeled Ia endings, although widely distributed, were located primarily on medium-sized dendrites, presumably within $300-600 \mu \mathrm{m}$ of the cell body. Light-level reconstruction studies (Burke et al., 1979, 1988; Brown and Fyffe, 1981; Grantyn et al., 1984) and electrophysiological studies (Jack et al., 1981a; Mendell and Henneman, 1971; Mendell and Weiner, 1976; Munson and Sypert, 1979) are in general agreement, although they have tended to emphasize the wide distribution of terminals, even within single Ia-motoneuron pairings. Additionally, a small but significant number of Ia boutons contact motoneuron somata (Burke et al., 1979; Conradi et al., 1983) and a few contact multiple dendritic profiles (Conradi et al., 1983), which can vary greatly in diameter (as seen in the present study). The broad variation in postsynaptic profile size observed in the present material supports this general terminal configuration.

A pattern of widely distributed contacts raises the question of whether there might be some form of systematic synaptic variation in relation to contact position. Rose and Neuber-Hess (1991) and Brännström (1993), in examinations of unlabeled tcrminals of ncck motoneuron and fast twitch limb motoneuron dendrites, respectively, reported a decrease in both profile and apposition size as one moves distally. These observations are related, but not identical, to two of our findings. First, the small number of Ia boutons that fell within the upper half of the range of volumes were all located quite proximally to the soma, on the basis of dendritic diameter or direct observation (Fig. $8 A$ ). These large boutons were reminiscent of the giant boutons that contact cells of Clarke's column (Kuno et al., 1973), which are also found only on or close to the soma. The more numerous, smaller boutons could be found contacting profiles of widely different sizes. This is consistent with other ultrastructural studies of motoneuron contacts (Conradi et al., 1979; Kellerth et al., 1979; Lagerback and Ulfhake, 1987). Second, both apposed surface area and percentage apposed surface decreased as dendritic diameter decreased (Fig. $8 B$ ), suggesting that these features decrease with increasing distance from the soma (Ulfhakc and Kellerth, 1981). Since both decreased, this could not be solely the result of finding smaller boutons distally, but rather implies that a smaller percentage of the surface area of those smaller boutons was devoted to contacting dendrites.

However, several factors implied that even though there was much less apposition between Ia boutons and distal dendrites, the synapses that were formed on them were potentially more efficacious. Three bouton characteristics that are presumably associated with general synaptic efficacy-percentage mitochondrial volume, vesicle density, and average individual $\mathrm{AZ}$ size-all exhibited significant, negative correlations with dendritic diameter, implying a positive correlation with distance from the soma (Fig. 8C). This type of relationship is suggested by the findings of two other groups, who examined unidentified contacts on motoneurons. Rose and Neuber-Hess (1991) observed that, for profiles containing spherical vesicles with intermediate (S-Ui) and high (S-Uh) densities, the S-Uh profiles were strongly localized on distal dendrites while the S-Ui profiles were only weakly localized there. Since the vesicle densities of Ia boutons stretch across both categories, this could represent a similar relationship. Antal et al. (1992), who reconstructed active zones on frog motoneurons, found a similar correlation between $A Z$ size and dendritic diameter.

These findings could contribute to the observation that longduration EPSPs, which are presumably generated on distal dendrites, are not significantly smaller than brief EPSPs, which would be generated on more proximal dendrites (Mendell and Weiner, 1976; Jack et al., 1981 a; Harrison et al., 1989). Increases in percentage mitochondrial volume, the packing density of vesicles, and AZ size could all act to counter the effect of increased electrotonic distance. Postsynaptic factors could also be involved. Jack et al. (1981a) have suggested that the uniformity of EPSP size is due to selective differences in postsynaptic receptor numbers, and Segev et al. (1990) have reported that models involving increases in the membrane resistance of distal dendrites reproduce experimental EPSPs well.

\section{Variation across the terminal field}

Several systematic differences in Ia afferent characteristics have been reported to be related to the distance from the fibers' DRE zone. Ishizuka et al. (1979) found that the diameter of the primary collateral branch decreased as the distance from the DRE 
increased, implying that the size of the collateral arbor and the number of boutons contained also decreased in a similar manner. Comparably, Lüscher et al. (1989) reported that the nearer a motoneuron was to the DRE zone of a stimulated fiber, the larger the observed mean EPSP amplitude (see also Scott and Mendell, 1976). Our findings suggest that the synapses located distant to the DRE zone could also be potentially less effective. The vesicle density of distant boutons was reduced by roughly one-third, both within the whole population and within a single fiber.

\section{Variation within the arbor}

The present results also suggest that bouton size (and thus potential efficacy) is related to the characteristics of other boutons within a group: the terminal arbor sprig. As reported, volume and related features (apposed surface area, $A Z$ number, vesicle number, surface area, and $P$ bouton number and surface) tended to decrease (or stay the same) as one moved downstream within a terminal branch, toward the terminal bouton, which usually had either the highest or lowest value (Fig. 9A). Hongo et al. (1987) and Nicol and Walmsley (1991) did not see a similar distribution of bouton sizes (based on light-level and ultrastructural profile measurements, respectively) of Ia terminal arbors in Clarke's column, except that terminal boutons were often either very large or very small. The pattern reported in our study could reflect developmental constraints. In the final branches of an arbor, some transported element(s) might be depleted, causing progressively less bouton growth. Terminal boutons could represent either a large bouton about to "pinch off" to form a new bouton (terminal boutons often had a "pinched" appearance at their tip), or the smallest, relatively inactive end.

\section{Conclusion}

The ultrastructural characteristics of our Ia boutons, even within an individual fiber or collateral arbor, displayed a high level of variability that on the surface would seem to complicate the task of understanding the basic elements of synaptic release. However, this variability becomes more interpretable when one considers that most of these characteristics covary in relation to bouton size, and that they often appear to be dependent on the positional context of the bouton-both within the presynaptic arbor and on the postsynaptic element. These factors seem to be mediated at the local level, relatively independent of the individual identity of the parent fiber or contacted cell, which does not seem to play a strong deterministic role in shaping bouton ultrastructure. Understanding the local mechanisms through which synaptic organelles can scale smoothly to reflect bouton size and adjust their characteristics in response to positional signals will be crucial in elucidating how synaptic strength is regulated.

\section{References}

Antal M, Kraftsik R, Székely G, van der Loos H (1992) Synapses on motoneuron dendrites in the brachial section of the frog spinal cord: a computer-aided electron microscopic study of cobalt-filled cells. J Neurocytol 21:34-49.

Applegate MD, Kerr DS, Landfield PW (1987) Redistribution of synaptic vesicles during long-term potentiation in the hippocampus. Brain Res 401:401-406.

Atwood HL, Marin L (1983) Ultrastructure of synapses with different transmitter-releasing characteristics on motor axon terminals of a crab, Hyas areneas. Cell Tissue Res 231:103-115.
Bailey CH, Chen M (1989) Time course of structural changes at identified sensory neuron synapses during long-term sensitization in $A p l y$ sia. J Neurosci 9:1774-1780.

Bower JM, Haberly LB (1986) Facilitating and nonfacilitating synapses on pyramidal cells: a correlation between physiology and morphology. Proc Natl Acad Sci USA 83:1115-1119.

Brännström T (1993) Quantitative synaptology of functionally different types of cat medial gastrocnemius $\alpha$-motoneurons. J Comp Neurol 330:439-454.

Brown AG, Fyffe REW (1981) Direct observations on the contacts made between Ia afferent fibres and $\alpha$-motoneurones in the cat's lumbosacral spinal cord. J Physiol (Lond) 313:121-140.

Burke RE, Walmsley B, Hodgson JA (1979) HRP anatomy of group Ia afferent contacts on alpha motoneurones. Brain Res 160:347-352.

Burke RE, Fleshman JW, Segev I (1988) Factors that control the efficacy of group Ia synapses in alpha-motoneurons. J Physiol (Paris) 83:133-140.

Calverley RKS, Jones DG (1990) Three-dimensional computer reconstruction of perforated synapses. In: Quantitative and qualitative microscopy (Conn PM, ed), pp 136-154. San Diego: Academic.

Chiang RG, Govind CK (1986) Reorganization of synaptic ultrastructure at facilitated lobster neuromuscular terminals. J Neurocytol 15: 63-74.

Clamann HP, Mathis J, Lüscher H-R (1989) Variance analysis of excitatory postsynaptic potentials in cat spinal motoneurons during post-tetanic potentiation. J Neurophysiol 61:403-4l6.

Clamann HP, Rioult-Pedotti M-S, Lüscher H-R (1991) The influence of noise on quantal EPSP size obtained by deconvolution in spinal motoneurons in the cat. J Neurophysiol 65:67-75.

Collins WF III, Honig MG, Mendell LM (1984) Heterogeneity of group Ia synapses on homonymous $\alpha$-motoneurons as revealed by high frequency stimulation of Ia afferent fibers. J Neurophysiol 52: 980-993.

Conradi S (1969) Ultrastructure of dorsal root boutons on lumbosacral motoneurons of the adult cat. Acta Physiol Scand [Suppl] 332:49-64.

Conradi S, Kellerth J-O, Berthold CH, Hammarberg C (1979) Electron microscopic studies of serially sectioned cat spinal å-motoneurons. IV. Motoneurons innervating slow-twitch (type S) units of the soleus muscle. J Comp Neurol 184:769-782.

Conradi S, Cullheim S, Gollvik L, Kellerth J-O (1983) Electron microscopic observations on the synaptic contacts of group Ia muscle spindle afferents in the cat lumbosacral spinal cord. Brain Res 265 31-39.

Davey DF, Bennett MR (1982) Variation in the size of synaptic contacts along developing and mature motor terminal branches. Dev Brain Res 5:11-22.

Desmond NL, Levy WB (1986) Changes in the postsynaptic density with long-term potentiation in the dentate gyrus. J Comp Neurol 253: $476-482$.

Fifková E, Van Harreveld A (1977) Long-lasting morphological changes in dendritic spines of dentate granule cells following stimulation of entorhinal area. J Neurocytol 6:211-230.

Floderus S (1944) Untersuchungen über den bau der menschlichen hypophyse mit besonderer berücksichtigung der quantitativen mikromorphologischen verhältnisse. Acta Pathol Microbiol Scand [Suppl] 53:1.

Fyffe REW, Light AR (1984) The ultrastructure of group Ia afferent fiber synapses in the lumbosacral spinal cord of the cat. Brain Res 300:201-209.

Govind CK, Chiang RG (1979) Correlation between presynaptic dense bodies and transmitter output at lobster neuromuscular terminals by scrial section electron microscopy. Brain Res 161:377-388.

Grantyn R, Shapovalov AI, Shiriaev BI (1984) Tracing of frog sensory-motor synapses by intracellular injection of horseradish peroxidase. J Physiol (Lond) 349:441-458.

Hamos JE, Van Horn S, Raczkowski D, Sherman SM (1987) Synaptic circuits involving an individual retinogeniculate axon in the cat. $J$ Comp Neurol 259:165-192.

Han H-Q, Nichols RA, Rubin MR, Bähler M, Greengard P (1991) Induction of formation of presynaptic terminals in neuroblastoma cells by synapsin IIb. Nature 349:697-700.

Harris KM, Stevens JK (1988) Dendritic spines of rat cerebellar Purkinje cells: serial electron microscopy with reference to their biophysical characteristics. J Neurosci 8:4455-4469.

Harris KM, Stevens JK (1989) Dendritic spines of CA1 pyramidal 
cells in the rat hippocampus: serial electron microscopy with reference to their biophysical characteristics. J Neurosci 9:2982-2997.

Harrison PJ, Jack JJB, Kullmann DM (1989) Monosynaptic EPSPs in cat lumbosacral motoneurones from group Ia afferents and fibres descending in the spinal cord. J Physiol (Lond) 412:43-63.

Henneman E, Mendell LM (1981) Functional organization of the motoneuron pool and its inputs. In: Handbook of physiology, Vol II, Sec 1, Pt 1, the nervous system, motor control (Brookhart JM, Mountcastle VB, ed), pp 423-507. Bethesda, MD: American Physiological Society.

Hillman DE, Chen S (1985) Compensation in the number of presynaptic dense projections and synaptic vesicles in remaining parallel fibres following cerebellar lesions. J Neurocytol 14:673-687.

Hillman H, Deutsch K (1978) Area changes in slices of rat brain during preparation for histology or electron microscopy. J Microsc 114:7884.

Hirst GDS, Redman SJ, Wong K (1981) Post-tetanic potentiation and facilitation of synaptic potentials evoked in cat spinal motoneuroncs. J Physiol (Lond) 321:97-109.

Holstege JC, Calkoen F (1990) The distribution of GABA in lumbar motoneuronal cell groups. A quantitative ultrastructural study in rat. Brain Res 530:130-137.

Hongo T, Kudo N, Sasaki S, Yamashita M, Yoshida K, Ishizuka N, Mannen $\mathrm{H}$ (1987) Trajectory of group Ia and Ib fibers from the hind-limb muscles at the L3 and L4 segments of the spinal cord of the cat. I Comp Neurol 262:159-194.

Ishizuka N, Mannen H, Hongo T, Sasaki S (1979) Trajectory of group Ia afferent fibers stained with horseradish peroxidase in the lumbosacral spinal cord of the cat: from serial sections. J Comp Neurol 186 189-211.

Jack JJB, Redman SJ, Wong K (1981a) The components of synaptic potentials evoked in cat spinal motoneurones by impulses in singlc group Ia afferents. J Physiol (Lond) 321:65-96.

Jack JJB, Redman SJ, Wong K (1981b) Modifications to synaptic transmission at group la synapses on cat spinal motoneurones by 4-aminopyridine. J Physiol (Lond) 321:111-126.

Kellerth J-O, Berthold CH, Conradi S (1979) Electron microscopic studies of serially sectioned cat spinal $\alpha$-motoneurons. III. Motoneurons innervating fast-twitch (type FR) units of the gastrocnemius muscle. J Comp Neurol 184:755-768.

Kellerth J-O, Conradi S, Berthold CH (1983) Electron microscopic studies of serially sectioned cat spinal $\alpha$-motoneurons. V. Motoneurons innervating fast-twitch (type FF) units of the gastrocnemius muscle. J Comp Neurol 214:451-458.

Koerber HR, Mendell LM (1991) Modulation of synaptic transmission at Ia-afferent fiber connections on motoneurons during high-frequency stimulation: role of postsynaptic target. J Neurophysiol 65:590597.

Kuno M (1964) Mechanism of facilitation and depression of the excitatory synaptic potential in spinal motoneurones. J Physiol (Lond) 175:100-112.

Kuno M, Munoz-Martinez EJ, Randic M (1973) Synaptic action on Clarke's column neurones in relation to afferent terminal size. J Physiol (Lond) 228:343-360.

Lagerback PA, Ulfhake B (1987) Ultrastructural observations on beaded $\alpha$-motoneuron dendrites. Acta Physiol Scand 129:61-66.

Lloyd DPC (1946) Integrative pattern of excitation and inhibition in two-neuron reflex arcs. J Neurophysiol 9:439-444.

Lnenicka GA, Atwood HL, Marin L (1986) Morphological transformation of synaptic terminals of a phasic motoneuron by long-term tonic stimulation. J Neurosci 6:2252-2258.

Lüscher H-R, Stricker C, Henneman E, Vardar U (1989) Influences of morphology and topography of motoneurons and muscle spindle afferents on amplitude of single fiber excitatory postsynaptic potentials in cat. Exp Brain Res 74:493-500.

Maxwell DJ, Bannatyne BA (1983) Ultrastructure of muscle spindle afferent terminations in lamina VI of the cat spinal cord. Brain Res 288:297-301.

Maxwell DJ, Christie WM, Short AD, Brown AG (1990) Direct observations of synapses between GABA-immunoreactive boutons and muscle afferent terminals in lamina VI of the cat's spinal cord. Brain Res 530:215-222

Mendell LM, Henneman E (1971) Terminals of single Ia fibers: location, density and distribution within a pool of 300 homonymous motoneurons. J Neurophysiol 34:171-187.
Mendell LM, Weiner R (1976) Analysis of pairs of individual TaE.P.S.P.s in single motoneurones. J Physiol (Lond) 255:81-104.

Munson JB, Sypert GW (1979) Properties of single central Ia afferent fibres projecting to motoncurones. J Physiol (Lond) 296:315-327.

Neale EA, Nelson PG, MacDonald RL, Christian CN, Bowers LM (1983) Synaptic interactions between mammalian central neurons in cell culture. III. Morphological correlates of quantal synaplic Iransmission. J Neurophysiol 49:1459-1468.

Nicol MJ, Walmsley B (1991) A serial section electron microscope study of an identified Ia afferent collateral in the cat spinal cord. $J$ Comp Neurol 314:257-277.

Örnung G, Ulfhake B (1990) Changes in size and shape during histochemical preparation for light and electron microscopy of neurons intracellularly labelled with horseradish peroxidase. Acta Physiol Scand 140:501-506.

Palay SL, Chan-Palay V (1974) Cerebellar cortex: cytology and organization. New York: Springer.

Peng Y, Frank E (1989a) Activation of $G \Lambda B \Lambda_{B}$ receptors causes presynaptic inhibition at synapses between muscle spindle afferents and motoneurons in the spinal cord of bullfrogs. J Neurosci 9:1502-1515.

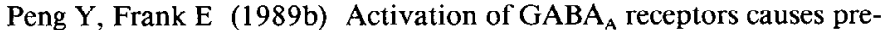
synaptic and postsynaptic inhibition at synapses between muscle spindle afferents and motoneurons in the spinal cord of bullfrogs. $J$ Neurosci 9:1516-1522.

Peters A, Harriman KM (1990) Different kinds of axon terminals forming symmetric synapses with the cell bodies and initial axon segments of layer II/III pyramidal cells. I. Morphometric analysis. J Neurocytol 19:154-174.

Peters A, Palay SL, Webster H deF (1976) The fine structure of the nervous system: the neurons and supporting cells. Philadelphia: Saunders.

Prochazka A, Wcstcrman RA, Ziccone SP (1976) Discharge of single hindlimb afferents in the freely moving cat. J Neurophysiol 39:1090 1104.

Propst JW, Ko C-P (1987) Correlations between active zone ultrastructure and synaptic function studied with freeze-fracture of physiologically identified neuromuscular junctions. J Neurosci 7:36543664.

Pun RYK, Neale EA, Guthrie PB, Nelson PG (1986) Active and inactive central synapses in cell culture. J Neurophysiol 56:12421256.

Redman S (1990) Quantal analysis of synaptic potentials in neurons of the central nervous system. Physiol Rev 70:165-198.

Redman S, Walmsley B (1983) Amplitude fluctuations in synaptic potentials evoked in cat spinal motoneurones at identified group Ia synapscs. J Physiol (Lond) 343:135-145.

Rose PK, Neuber-Hess M (1991) Morphology and frequency of axon terminals on the somata, proximal dendrites, and distal dendrites of dorsal neck motoneurons in the cat. J Comp Neurol 307:259-280.

Rudomin P (1990) Presynaptic control of synaptic effectiveness of muscle spindle and tendon organ afferents in the mammalian spinal cord. In: The segmental motor system (Binder MD, Mendell LM, eds), pp 349-380. New York: Oxford UP.

Scott JG, Mendell LM (1976) Individual EPSPs produced by single triceps surae Ia afferents in homonymous and heteronymous motoneurons. J Neurophysiol 39:679-692.

Segev I, Flcshman JJW, Burke RE (1990) Computer simulation of group Ia EPSPs using morphologically realistic models of cat $\alpha$-motoneurons. J Neurophysiol 64:648-660.

Small JV (1968) Measurements of section thickness. Proc 4th Eur Cong Elect Microsc 1:609.

Streichert LC, Sargent PB (1989) Bouton ultrastructure and synaptic growth in a frog autonomic ganglion. J Comp Neurol 281:159-168.

Tracey DJ, Walmsley B (1984) Synaptic input from identified muscle afferents to neurones of the dorsal spinoccrcbellar tract in the cat. $J$ Physiol (Lond) 350:599-614.

Tse FW, Marin L, Jahromi SS, Atwood HL (1991) Variation in terminal morphology and presynaptic inhibition at crustacean neuromuscular junctions. J Comp Neurol 304:135-146.

Ueda T, Greengard P (1977) Adenosine 3',5' monophosphate regulated phosphoprotein system of neuronal membranes. I. Solubilization, purification and some properties of an endogenous phosphoprotein. J Biol Chem 252:5155-5163.

Ulfhake B, Kellerth J-O (1981) Quantitative light microscopic study 
of the dendrites of cat spinal á-motoneurons after intracellular staining with horseradish peroxidase. J Comp Neurol 202:571-583.

Vaughn JE, Grieshaber JA (1972) An electron microscopic investigation of glycogen and mitochondria in developing and adult spinal motor neuropil. J Neurocytol 1:397-412.

Walmsley B, Wieniawa-Narkiewicz E, Nicol MJ (1985) The ultrastructural basis for synaptic transmission between primary muscle afferents and neurons in Clarke's column of the cat. J Neurosci 5:2095-2106.
Walmsley B, Edwards FR, Tracey DJ (1988) Non-uniform release probabilities underlie quantal synaptic transmission at a mammalian excitatory synapse. J Neurophysiol 60:889-908.

Yeow MBL, Peterson EH (1991) Active zone organization and vesicle content scale with bouton size at a vertebrate central synapse. J Comp Neurol 307:475-486. 